\title{
A Bioinspired 10 DOF Wearable Powered Arm Exoskeleton for Rehabilitation
}

\author{
Soumya Kanti Manna and Subhasis Bhaumik \\ School of Mechatronics \& Robotics, Bengal Engineering \& Science University, Shibpur, Howrah 711103, India \\ Correspondence should be addressed to Soumya Kanti Manna; soumyakanti.mid@gmail.com
}

Received 31 May 2013; Revised 7 October 2013; Accepted 8 October 2013

Academic Editor: Oliver Sawodny

Copyright (C) 2013 S. K. Manna and S. Bhaumik. This is an open access article distributed under the Creative Commons Attribution License, which permits unrestricted use, distribution, and reproduction in any medium, provided the original work is properly cited.

The developed exoskeleton device (Exorn) has ten degrees of freedom to control joints starting from shoulder griddle to wrist to provide better redundancy, portability, and flexibility to the human arm motion. A 3D conceptual model is being designed to make the system wearable by human arm. All the joints are simple revolute joints with desired motion limit. A Simulink model of the human arm is being developed with proper mass and length to determine proper torque required for actuating those joints. Forward kinematics of the whole system has been formulated for getting desired dexterous workspace. A proper and simple Graphical User Interface (GUI) and the required embedded system have been designed for providing physiotherapy lessons to the patients. In the literature review it has been found that researchers have generally ignored the motion of shoulder griddle. Here we have implemented those motions in our design. It has also been found that people have taken elbow pronation and supination motion as a part of shoulder internal and external rotation though both motions are quite different. A predefined resolved motion rate control structure with independent joint control is used so that all movements can be controlled in a predefined way.

\section{Introduction}

It is seen that a major stroke is viewed by more than half of those at risk as being worse than death. Paralysis is caused due to complete loss of muscle function. In both cases patients have stiff muscles which restrict them from any physical movement of the affected part. Even the patients suffering from spinal cord injury or several nerve diseases may also lose their muscle strength gradually. According to Krakauer [1] the degree of improvement at 6 months is best predicted by the motor deficit at 1 month despite standard rehabilitative interventions in the ensuing 5 months. It is already proved that if they are under the process of rehabilitation for several months after stroke, their active range of motion as well as muscle strength can increase significantly. The training includes all the orthopedic and neurological lessons so that it is effective to the human muscle treatment. The rehabilitation training is generally performed by a physiotherapist, but the duration of the training is not adequate due to the fatigue of the therapist. It is observed that a physiotherapist can perform the training for 8-10 hours a day and can provide service to 2 to 3 patients at a very high cost. They may even omit certain exercises which are essential to the patients. The person also does not get repetitive and accurate movement sessions in case of a manual interaction. Considering time, cost, repeatability, reproducibility, and accuracy, robotically assisted rehabilitation process is far better than human assisted training process. Several assistive devices like ARMin, MEDARM, and SMA are already being developed for the rehabilitation process. But each one of them has several advantages and disadvantages. The purpose of Exorn is to provide maximum degree of freedom so that the device becomes as redundant as human hand and can provide better rehabilitation process in future.

\section{The Literature Review}

Until now two types of design are being proposed. First one is an exoskeleton structure connected to a base platform from where all the actuators are being controlled taking the platform as a reference. Second one is a portable structure wearable by a human. First one is a bulky system like ARMin [2], MEDARM [3], and Sarcos Master Arm [4] where the motion is stable, but it cannot be effective as an assistive 
device for the paralyzed people. Also there is a problem of misalignment of the system with the human hand at the time of joint movement due to which there is a possibility of injury [5]. In some design the number of degree of freedom is restricted to certain directions [6]. It will omit certain necessary movements which are very much needed for the proper rehabilitation process including solder griddle movement. Hydraulic and pneumatic actuators/devices like NEUROExos [7] have a big cylinder and pump connected with it to provide actuation signal. This kind of system is impossible to relocate with the human movement to make system portable.

Mistry et al. have already carried out experiments on joint space force field trajectories [4] to estimate kinematics and dynamics of the human arm with several trails in case of 3D movement of the human arm. Parallel manipulators have a problem of high stiffness and range of motion with several restrictions. In case of a serial manipulator if the offset between actuators is less then it acts like a joint with several DOFs. Yang et al. control puma manipulator using arm exoskeleton because control system is quite the same for both the cases [9]. Pneumatic and hydraulic system are used for actuation. electroactive polymer (EAP) has been used for haptic device. Ball et al. have developed actuation system using cables which in reverse increases the stiffness factor by 10 to 12 [6]. So it is expected that motor driven system should be used to make the exoskeleton robot simple. Researchers are also trying to control the actuation through EMG sensors using fuzzy algorithm [10]. Generally impedance control is usually implemented in which the Cartesian forces applied at the joint are converted into joint torque commands using the Jacobian [1] matrix. The main disadvantage of impedance control is that good force replication requires compensation of the natural dynamics of the exoskeleton, such as gravity loading and drives frictions. The Exoskeleton Arm-Master [12] and the L-EXOS Exoskeleton [13] are classic examples of exoskeletons that use this approach. An alternative approach of joint control is called "admittance" control which is primarily used to control manipulators used as large reach haptic devices. However, it has the major drawback of instability for high admittance (low impedance), which is the opposite of impedance control [14]. The Sensor Arm [15] is an example of an exoskeleton implementing this approach.

\section{Mechanical Model}

The whole structure is made of Perspex which is lighter in weight and much hardy than any other similar material. High torque DC geared motor is used for controlling the joint movements of shoulder griddle, glenohumeral joint, and elbow joint for gross positioning. For the motion of wrist joint small BLDC servo motor is being used for fine positioning. Gear drives are made of Nylon 101 material. As there are some joint limitations because of mechanical constraints, it cannot give the same motion as human joint range as shown in Table 1. In few locations suspensors are used to sustain any jerk and to incorporate the variation of link. Human joint of two or more degrees of freedom is

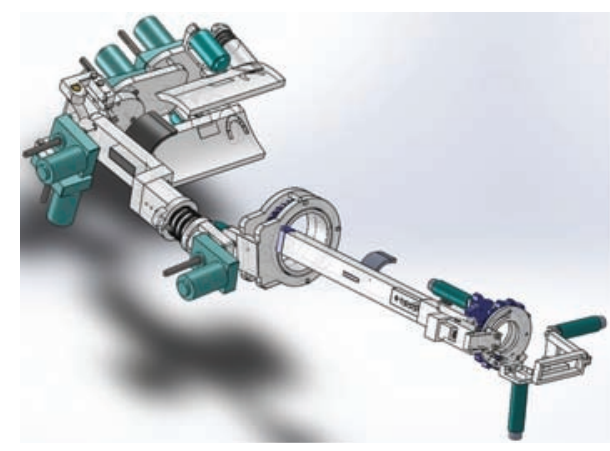

FIgURE 1: Total exoskeleton system.

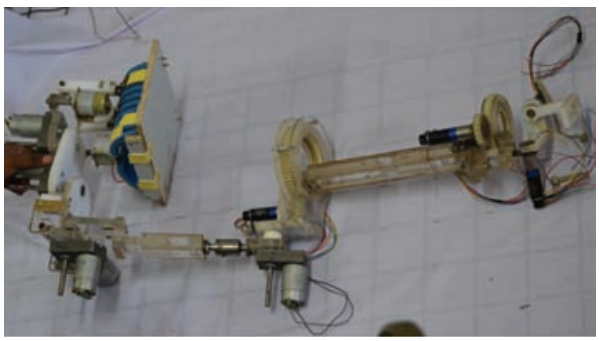

FIGURE 2: Manufacturing model of exoskeleton.

being replaced by serial manipulator with several actuators. The offset between those actuators is less so that it can act like a single joint actuator with several degrees of freedom. The axis of rotation of human joint has been considered for placement of the actuators. In this model, the length of upper arm and forearm supporting link can be varied according to the different human arm length. The CAD model of Exorn and manufactured model are shown in Figures 1 and 2. The other parts of exoskeleton structure and its manufactured models are shown in Figures 3, 4, 5, 6, 7, 8, 9, and 10. From those given figures the design of any particular joint model can be analyzed.

Shoulder griddle is one of the vital joints with two degrees of freedom. Actuator 1 is used for giving the elevation and depression motion in vertical direction and actuator 2 is used for scapular abduction and adduction in horizontal direction. For elevation and depression screw nut mechanism is being used. Glenohumeral joint is a ball-socket joint having three degrees of freedom. The actuators required for giving the motion to this joint are shown in Figure 5. Actuators 3 to actuator 5 are DC motors used for three different rotations. Actuator 6 is a BLDC motor used for shoulder internal and external rotation. One hollow cylindrical spur gear meshes with a small pinion gear which is driven by actuator 6 . The length between shoulder joint and elbow is changeable. Actuator 7 is a DC motor used for controlling elbow flexion and extension as shown in Figure 7. The same kind of technique is applied for forearm pronation and supination as that happened in the case of shoulder internal and external rotation. A suspensor is attached to upper portion of elbow joint to make it jerk-free and incorporate the change in arm length. Wrist joint has two degrees of freedom in two planes. 


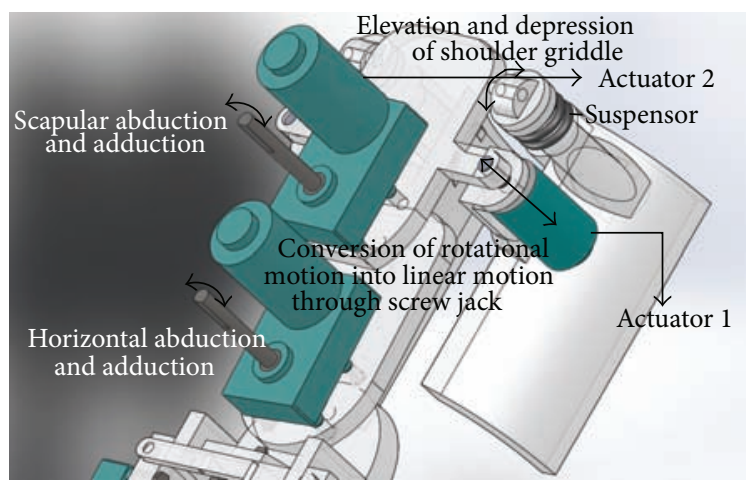

Figure 3: Shoulder griddle joint model.

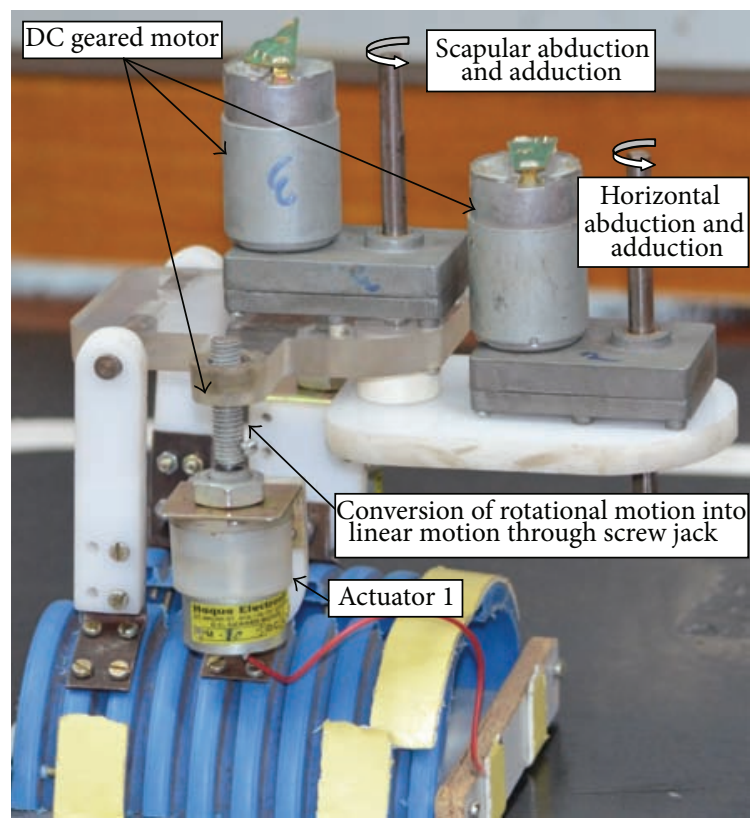

FIGURE 4: Manufactured model of shoulder griddle.

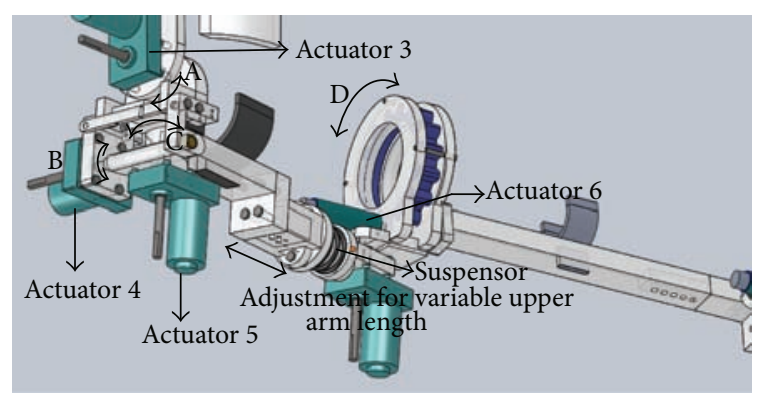

(A) Horizontal abduction and adduction

(B) Vertical abduction and adduction

(C) Forward flexion and extension

(D) External and internal rotation

FIgURE 5: Glenohumeral joint model.

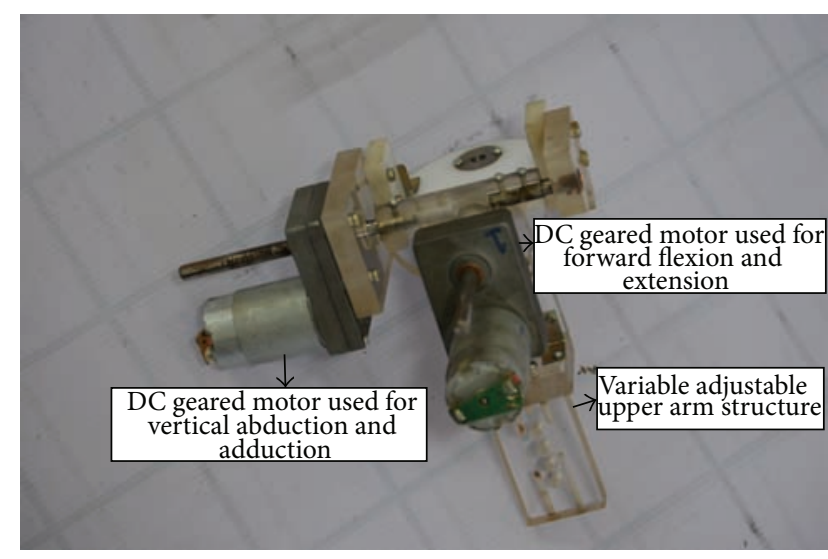

Figure 6: Manufactured model of glenohumeral joint.

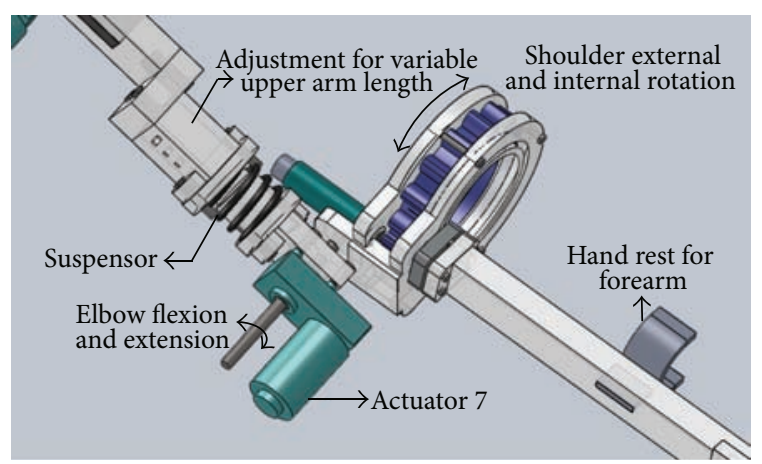

FIGURE 7: Elbow joint model.

Actuators 9 and 10 are used for providing those motions. Here we can see that all the actuators are dedicated to give the motion in all directions according to the different movements of human arm as shown in Figure 11.

Weight of the Prototype: $5 \mathrm{~kg}$.

Specification of the DC Geared Motor

$$
\begin{aligned}
& \text { Weight }-500 \mathrm{gm} \\
& \text { Speed- } 10 \mathrm{rpm} \\
& \text { Torque }-100 \mathrm{~kg}-\mathrm{cm} \text { at } 4 \text { ampere (Max). }
\end{aligned}
$$

\section{Specification of BLDC Motor}

$$
\begin{aligned}
& \text { Company-Faulhaber } \\
& \text { Weight- } 500 \mathrm{gm} \\
& \text { Speed- } 10 \mathrm{rpm} \\
& \text { Torque- }-100 \mathrm{~kg}-\mathrm{cm} \text { at } 4 \text { ampere (Max). }
\end{aligned}
$$

Gears are made up of Nylon 101. Structures are used for twisting moment at human elbow and wrist with the help of gear arrangement which provide better flexibility and strength. 


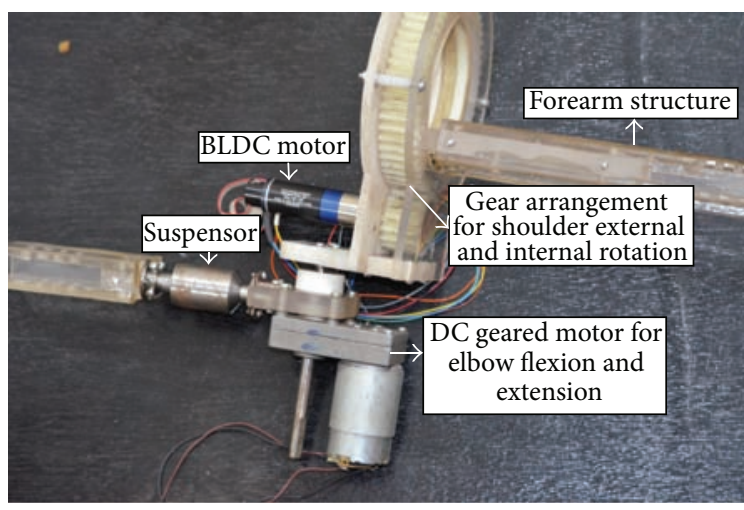

Figure 8: Manufactured model of elbow joint.

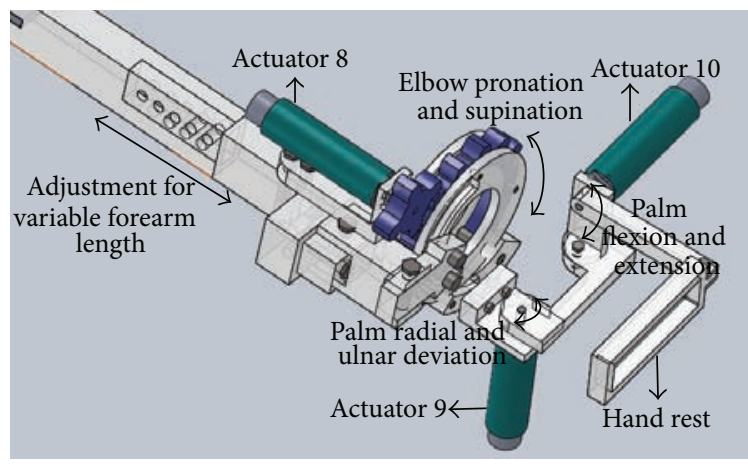

FIGURE 9: Wrist joint model.

Specification of Nylon 101

$$
\begin{aligned}
& \text { Tensile strength: } 79289709 \mathrm{~N} / \mathrm{m}^{2} \\
& \text { Mass density: } 1150 \mathrm{Kg} / \mathrm{m}^{3} \\
& \text { Elastic modulus: } 1000000000 \mathrm{~N} / \mathrm{m}^{2} \\
& \text { Yield strength: } 60000000 \mathrm{~N} / \mathrm{m}^{2} \\
& \text { Turn ratio at the elbow joint: } 35: 8 \\
& \text { Turn ratio at wrist joint: } 15: 4 \text {. }
\end{aligned}
$$

At the shoulder joint bush is used to provide the support to the joint motor axis. It is made up of brass to reduce the wear and tear between perspex and motor spindle. One cylindrical rod of the same material moves inside the bush and provides the support to the other end of structure at the time of joint flexion and extension.

The whole body of Exorn is made up of perspex. It is hardy and elastic. It gives less weight in respect to aluminum. Perplex sheet is cut into different pieces and attached with each other through industrial gum and nut (M4 thread). Three different thickness perspex sheets have been used for the structure. Higher width is used at the arm structure to give better support and the lower one is used for hand structure:

$$
\begin{aligned}
& \text { Type } 1 \text {-Width } 5 \mathrm{~mm} \\
& \text { Type } 2 \text {-Width } 10 \mathrm{~mm} \\
& \text { Type } 3 \text {-Width } 20 \mathrm{~mm} \text {. }
\end{aligned}
$$

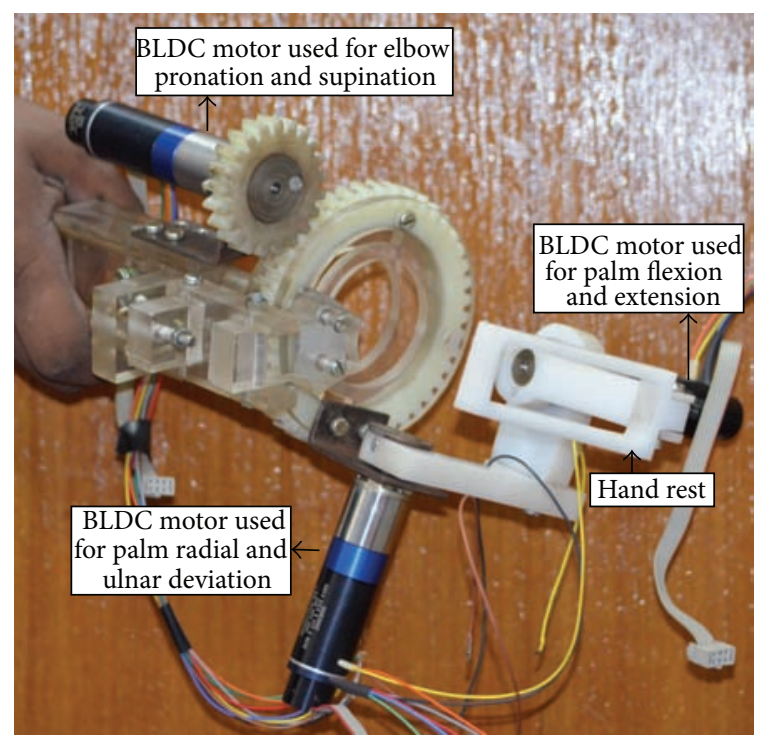

FIGURE 10: Manufactured model of wrist joint.

\author{
Specification of Perspex (TM) GS Acrylic Cast Sheet \\ Tensile strength: $75000000 \mathrm{~N} / \mathrm{m}^{2}$ \\ Density: $1190 \mathrm{Kg} / \mathrm{m}^{3}$.
}

Size of the Exoskeleton. The size of the exoskeleton (approximately $96.73 \mathrm{~cm}$ ) has been taken as per the standard length of a human arm and it can be varied from person to person:

$$
\begin{aligned}
& \text { Length of shoulder griddle: } 0.129 H \\
& \text { Length of upper arm: } 0.186 H \\
& \text { Length of forearm: } 0.146 H \\
& \text { Length of hand: } 0.108 H \text {. }
\end{aligned}
$$

Here $H$ is defined as the height of the human arm and if we consider the height of a standard human as $170 \mathrm{~cm}$, the length will be approximately $96.73 \mathrm{~cm}$. Obviously the length of human arm is different from person to person. But as we have made a physical system, we have taken the standard length. But the system has a provision so that it is wearable to all the people of variable arm length which has been discussed in the portion of mechanical model.

\section{Kinematic Analysis of Exorn}

Kinematic model of Exorn is designed according to the anthropometric data of standard human arm. The mechanical structure is such that it can align with human arm and can provide the desirable joint motion. Some mechanical barrier is located to restrict the joint from hyperextension. Here the forward kinematics of the whole system is discussed which provides the end point position and orientation due to several joint motions. It is basically acting as a series manipulator. The kinematic relation of a manipulator is represented by $\dot{x}=J \dot{\theta}$. 


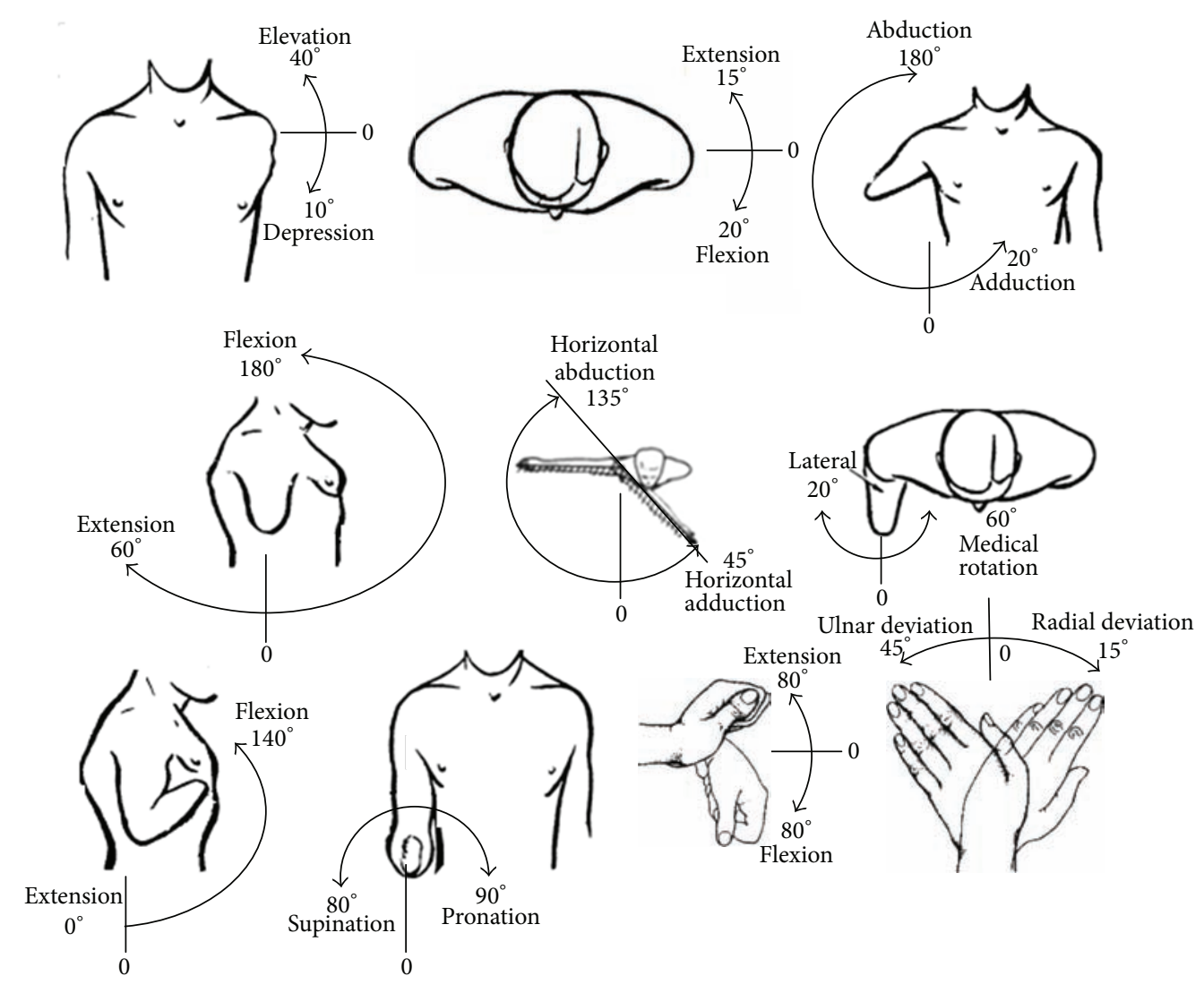

Figure 11: Different motions of human arm.

$\dot{x}$ is the $m$ dimensional vector specifying the task velocity of end effector. $\dot{\theta}$ is $n$ dimensional vector representing the joint velocity. $J$ is the $m$ by $n$ Jacobian matrix. For a redundant manipulator $n$ is always greater than $m$. Here the kinematic redundancy is 3 .

4.1. D-H Parameter of the 3D Model. To do kinematic analysis of the whole system it is essential to derive $\mathrm{D}-\mathrm{H}$ parameter of the whole system. The coordinate system of the whole structure is shown in Figure 12. The coordinate structure of the exoskeleton system is based on $3 \mathrm{D}$ conceptual model of Exorn. D-H parameters of the structure are shown in Table 2. It is essential to calculate the position and orientation of the end point in $3 \mathrm{D}$ space with respect to the reference coordinate.

4.2. Transformation Matrix Generation. For getting the position and orientation of the end point of Exorn system homogeneous transformation matrix is considered. Each homogeneous transformation matrix was calculated for the position and orientation of present frame with respect to the previous frame. It is a $4 \times 4$ matrix. The column ${ }^{i-1} d_{i}$ is position of the end point and ${ }^{i-1} R_{i}$ is the orientation of end point in $3 \mathrm{D}$ space. The transformation matrix is ${ }^{i-1} A_{i}$ :

$$
{ }^{i-1} A_{i}=\left[\begin{array}{cc}
{ }^{i-1} R_{i} & { }^{i-1} d_{i} \\
0 & 1
\end{array}\right]_{4 \times 4} .
$$

The homogeneous matrix is being explained as

$$
\begin{aligned}
& { }^{i-1} A_{i}=D_{z i-1, d i} * R_{z i-1, \theta i} * D_{x i-1, a i} * R_{x i-1, \alpha i} \\
& =\left[\begin{array}{cccc}
\cos \theta_{i} & -\sin \theta_{i} \cos \alpha_{i} & \sin \theta_{i} \sin \alpha_{i} & a_{i} \cos \theta_{i} \\
\sin \theta_{i} & \cos \theta_{i} \cos \alpha_{i} & -\cos \theta_{i} \sin \alpha_{i} & a_{i} \sin \theta_{i} \\
0 & \sin \alpha_{i} & \cos \alpha_{i} & d_{i} \\
0 & 0 & 0 & 1
\end{array}\right], \\
& { }^{i-1} d_{i}=\left[\begin{array}{c}
a_{i} \cos \theta_{i} \\
a_{i} \sin \theta_{i} \\
d_{i}
\end{array}\right] \\
& { }^{i-1} R_{i}=\left[\begin{array}{ccc}
\cos \theta_{i} & -\sin \theta_{i} \cos \alpha_{i} & \sin \theta_{i} \sin \alpha_{i} \\
\sin \theta_{i} & \cos \theta_{i} \cos \alpha_{i} & -\cos \theta_{i} \sin \alpha_{i} \\
0 & \sin \alpha_{i} & \cos \alpha_{i}
\end{array}\right] \text {. }
\end{aligned}
$$

For calculating the homogeneous matrix due to 10 degrees of freedom the 10 homogeneous matrixes are been multiplied sequentially. The final matrix is $T$ which is represented as

$$
T={ }^{0} A_{1} \times{ }^{1} A_{2} \times{ }^{2} A_{3} \times{ }^{3} A_{4} \times{ }^{4} A_{5} \cdots \times{ }^{9} A_{10} .
$$

The calculation can be made easy by dividing the total multiplication into two parts such that $T={ }^{0} A_{5} \times{ }^{5} A_{11}$. As it is a $10 \mathrm{DOF}$ system. Finally $T$ matrix of the end point of Exorn is represented with respect to reference and its upper 3 values of last column are position vector of end point related to world frame. 


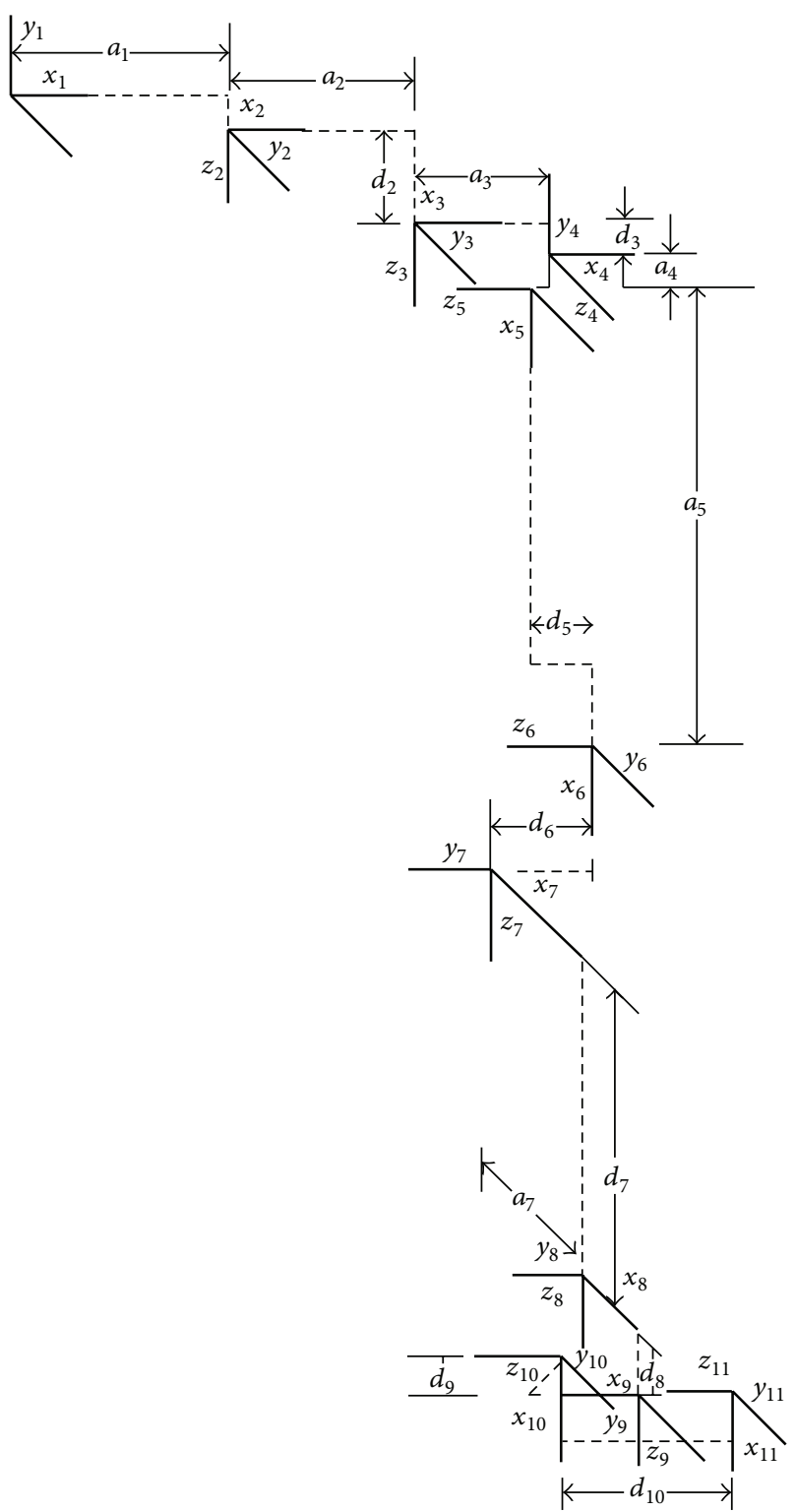

Figure 12: Coordinate system of 3D model.

\section{Simulation Model of Human Arm}

A human arm model is being made in Simulink to determine the required torque to move a joint. The length of upper arm, lower arm, and hand is considered according to the anthropometric data of standard human arm. The inertia matrix of each segment is determined according to the mass of that segment and length of the centre of gravity from the proximal end as per Table 3. In Simulink, it is possible to provide motions in terms of velocity to joint actuator and from the joint sensor torque level change is noted. The Simulink model of human arm is shown in Figure 13. Maximum amount of torque is needed to move those joints which are in vertical direction. Here only joint motion related to shoulder, elbow, and wrist flexion and extension is considered. Next those internal and external rotations are
TABLE 1: Comparative study between joints of human arm and Exorn.

\begin{tabular}{|c|c|c|c|}
\hline $\begin{array}{l}\text { Actuator } \\
\text { number }\end{array}$ & Movement & $\begin{array}{l}\text { Human joint } \\
\text { range (Deg) }\end{array}$ & $\begin{array}{c}\text { Exorn range } \\
\text { (deg) }\end{array}$ \\
\hline \multicolumn{4}{|c|}{ Shoulder griddle movements } \\
\hline \multirow{2}{*}{ Actuator 1} & Elevation & 40 & 30 \\
\hline & Depression & 10 & 10 \\
\hline \multirow{2}{*}{ Actuator 2} & Scapular abduction & 20 & 20 \\
\hline & Scapular adduction & 15 & 15 \\
\hline \multicolumn{4}{|c|}{ Shoulder joint movements } \\
\hline \multirow{2}{*}{ Actuator 3} & Horizontal abduction & 135 & 90 \\
\hline & Horizontal adduction & 45 & 45 \\
\hline \multirow{2}{*}{ Actuator 4} & Vertical abduction & 180 & 160 \\
\hline & Vertical adduction & 20 & 0 \\
\hline \multirow{2}{*}{ Actuator 5} & Forward flexion & 180 & 90 \\
\hline & Forward extension & 60 & 60 \\
\hline \multirow{2}{*}{ Actuator 6} & External rotation & 90 & 90 \\
\hline & Internal rotation & 20 & 20 \\
\hline \multicolumn{4}{|c|}{ Elbow joint movements } \\
\hline \multirow{2}{*}{ Actuator 7} & Elbow flexion & 140 & 120 \\
\hline & Elbow extension & 0 & 0 \\
\hline \multirow{2}{*}{ Actuator 8} & Forearm pronation & 90 & 90 \\
\hline & Forearm supination & 80 & 80 \\
\hline \multicolumn{4}{|c|}{ Wrist joint movements } \\
\hline \multirow{2}{*}{ Actuator 9} & Palm radial deviation & 15 & 10 \\
\hline & palm ulnar deviation & 45 & 30 \\
\hline \multirow{2}{*}{ Actuator 10} & Palm flexion & 80 & 80 \\
\hline & Palm extension & 80 & 80 \\
\hline \multicolumn{4}{|c|}{ TABLE 2: D-H parameter of Exorn. } \\
\hline$a_{i}(\mathrm{~cm})$ & $\alpha_{i}(\mathrm{deg})$ & $d_{i}(\mathrm{~cm})$ & $\theta_{i}(\mathrm{deg})$ \\
\hline 10 & 90 & 0 & $\Theta_{1}$ \\
\hline 12 & 0 & 5 & $\Theta_{2}$ \\
\hline 6 & 90 & 2 & $\Theta_{3}$ \\
\hline 3 & -90 & 0 & $\Theta_{4}$ \\
\hline 31 & 0 & -2.5 & $\Theta_{5}$ \\
\hline 0 & 90 & 6 & $\Theta_{6}$ \\
\hline 3 & 0 & 35 & $\Theta_{7}$ \\
\hline 0 & 90 & 2.5 & $\Theta_{8}$ \\
\hline 0 & -90 & 4 & $\Theta_{9}$ \\
\hline 0 & 0 & 8 & $\Theta_{10}$ \\
\hline
\end{tabular}

being taken care of. In exoskeleton system those motions cannot be controlled from the fixed end due to its twisting type. Therefore the end effector should be rotated with respect to fixed end.

The Simulink blocks used for making the human arm model are shown in Figures 14 and 15. A joint actuator block is connected to provide the actuation signal and joint sensor block is attached to measure the computed torque. In order to make a joint with several DOFs, several bodies of zero mass and zero length with actuator block of different axis of 


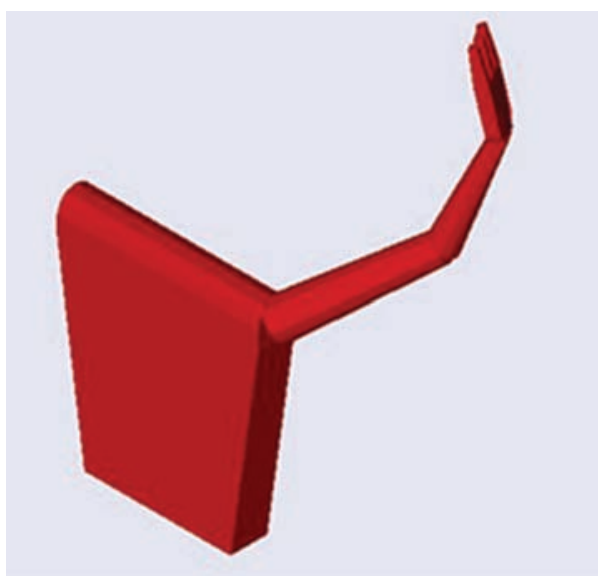

(a)

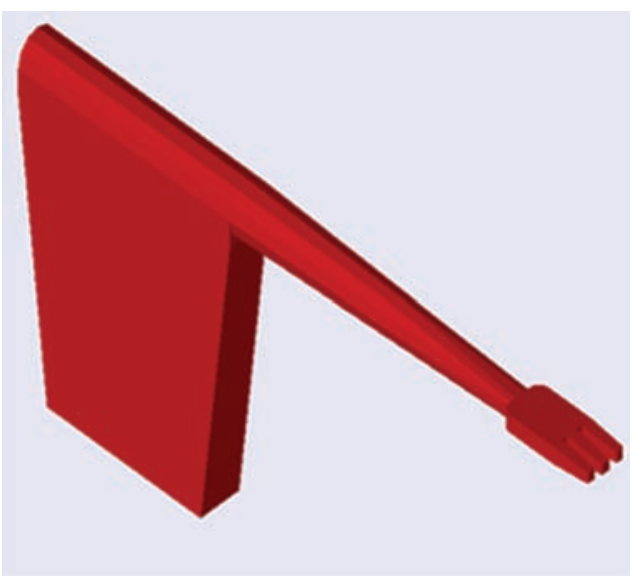

(b)

FIGURE 13: (a) Simulink model of human hand, (b) human hand position at zero position.

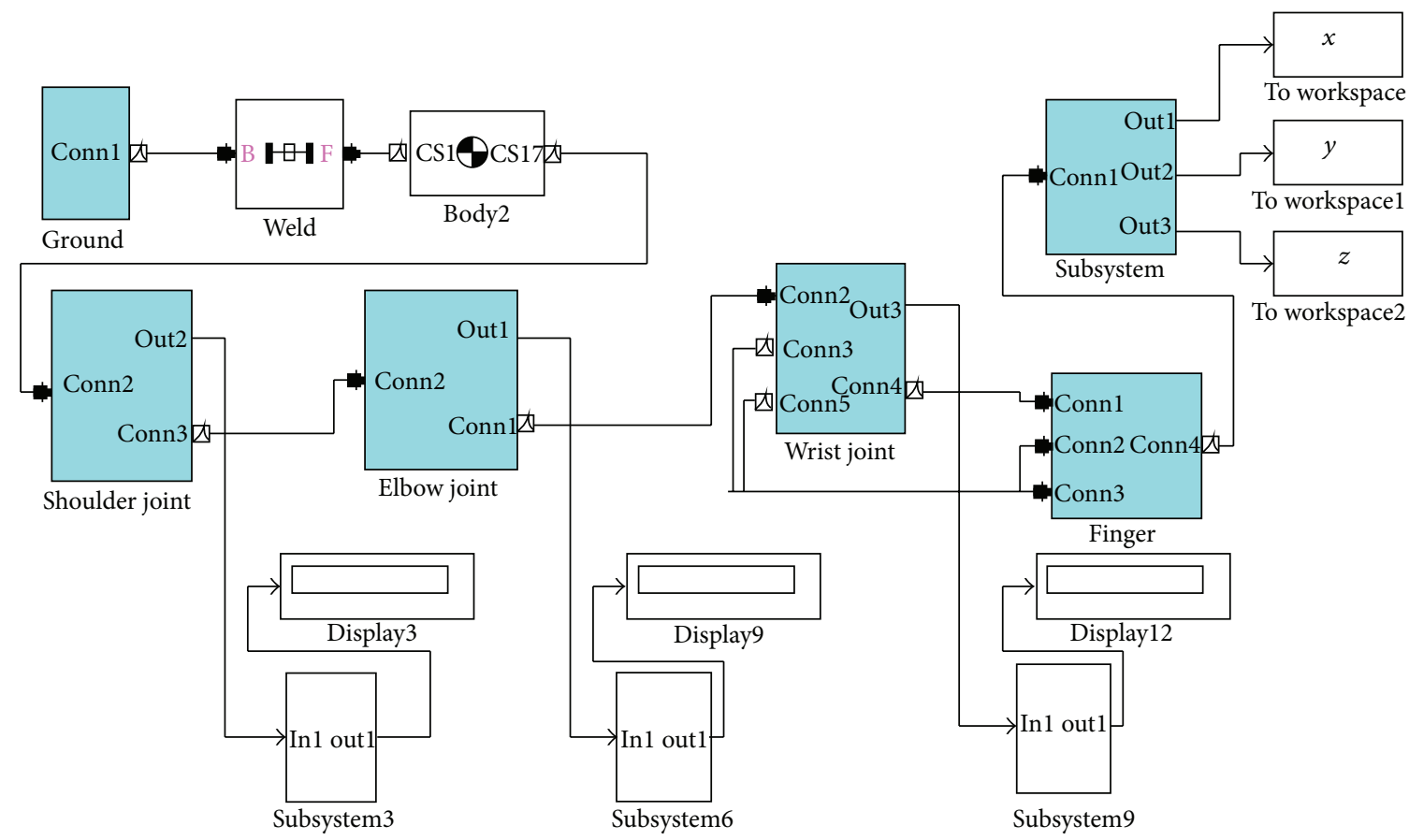

FIGURE 14: Human arm model in Simulink

rotations are connected. Here in Figure 15 body 1 and body 2 have zero length and zero mass. Only body 3 is the actual body. It is under every human arm joint. Body sensor is attached at the end point to get points in 3D space at the time of motion.

\section{Embedded System}

A PC based control system is being developed to provide particular orthopedic lesson. First of all command signal from PC is transmitted to the master controller. Master controller activates those joints which are needed to achieve the desired motion. It sends the command bits in a package through serial communication. Enable signal is being sent to all the local controllers, but only few are being activated as per command with the help of multiprocessor communication technique. All the motor controllers are connected in a daisy chain network that means $T_{x}$ and $R_{x}$ pins of master controller are connected to all $R_{x}$ and $T_{x}$ pins of each controller, respectively. Each controller has a particular node as an activating signal. When the master controller sends the activation signal, the particular motor controller with that particular node is activated.

The interfacing circuit between microcontroller and motor driver is shown in Figures 16(a) and 16(b). Driver IC has 4 input pins and 2 enable pins. Here all the inputs pins and enable pins are connecting to port 0 and port 1 . Here all the enable pins are sorted and connected through one port pin. 


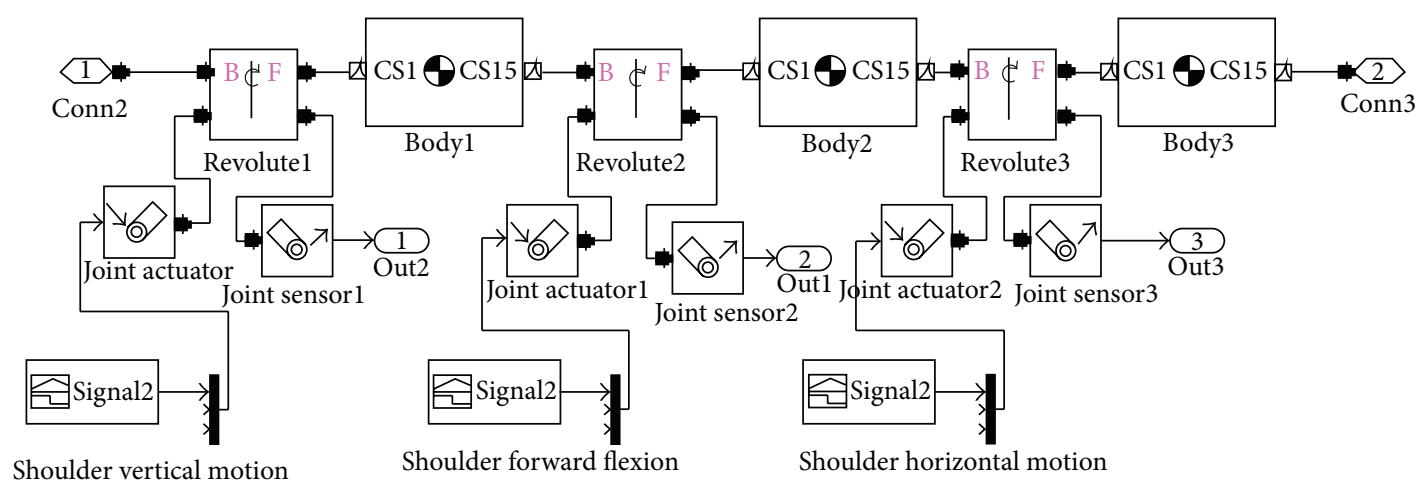

FIGURE 15: Block diagram below each human joint.

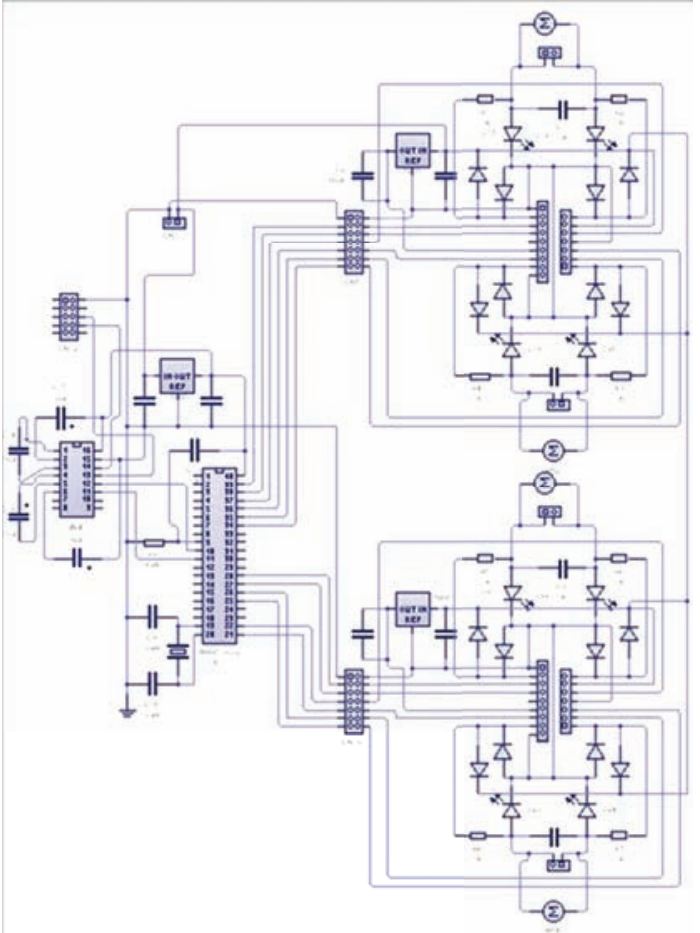

(a)

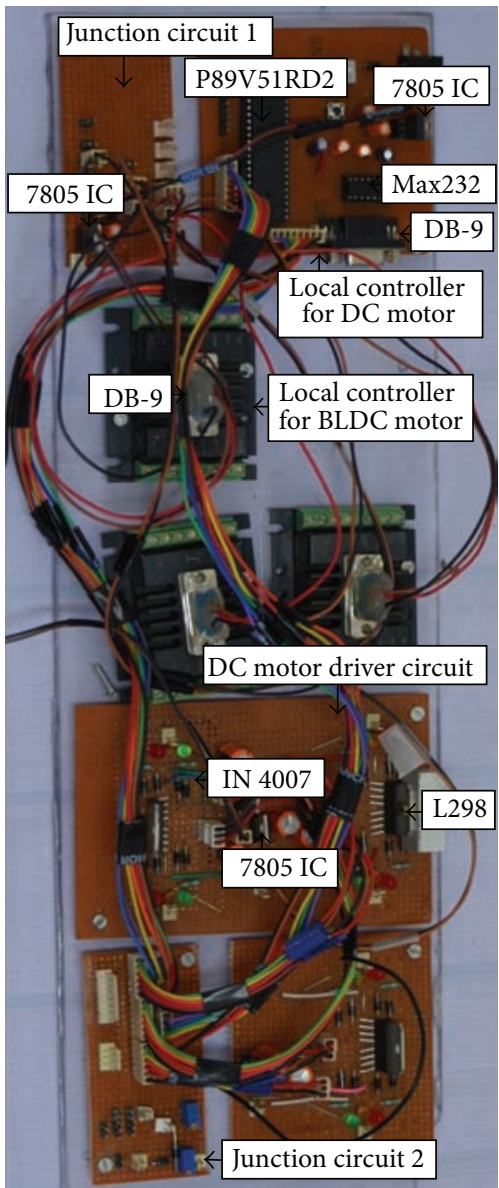

(b)

FIGURE 16: (a) Schematic design of interfacing circuit between microcontroller and motor driver. (b) Developed interfacing circuit of microcontroller.

In this case all the enable pins become activated at one time. So the motion of motor can be controlled by changing driver inputs. Those inputs are amplified from $5 \mathrm{~V}$ to $12 \mathrm{~V}$ to run the motor in clockwise and anticlockwise manner (Figure 17). As shown in the figure one dedicated 7805 IC (Voltage regulator) is connected to microcontroller for $5 \mathrm{~V}$ power supply. A serial IC MAX232 is connected to the microcontroller to convert the RS232's signals to TTL voltage levels that is acceptable to 8051 microcontroller $T_{x}$ and $R_{x}$ pins.

A bidirectional $\mathrm{H}$ bridgeDC motor control circuit is shown in Figures 17(a) and 17(b). The circuit is based on the IC L298 from ST Microelectronics L298. It is a dual full bridge driver that has a wide operating voltage range and can handle load currents up to $3 \mathrm{~A}$. The IC also features low 


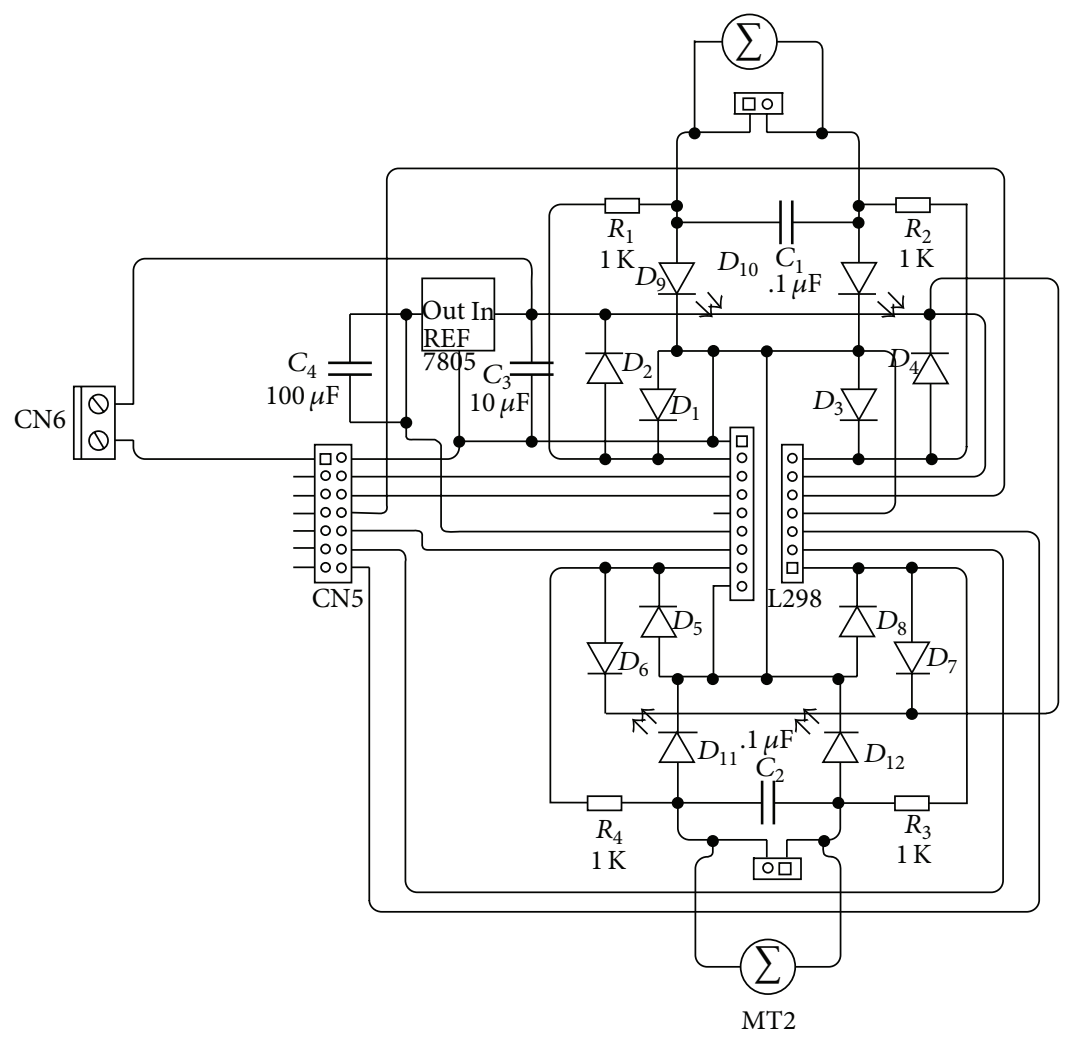

(a)

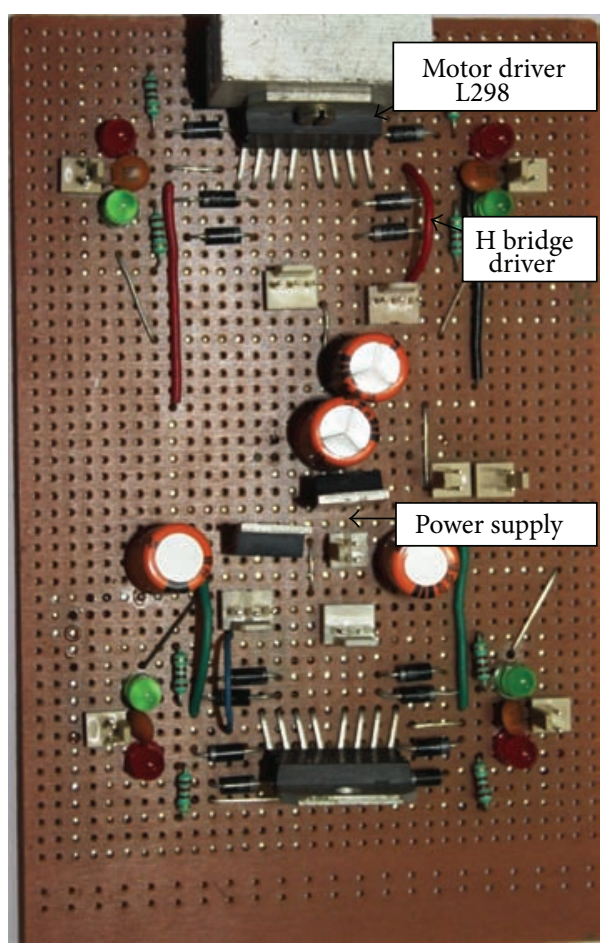

(b)

FIgURE 17: (a) Schematic design of motor driver circuit. (b) Developed motor driver circuit.

TABLE 3: Segment mass and lengths of human arm [8].

\begin{tabular}{|c|c|c|c|c|c|c|}
\hline \multirow{2}{*}{ Segment } & \multirow{2}{*}{ Segment mass/total body mass } & \multicolumn{2}{|c|}{ Centre of mass/segment length } & \multicolumn{3}{|c|}{ Radius of gyration/segment length } \\
\hline & & Proximal & Distal & $\mathrm{CM}$ & Proximal & Distal \\
\hline Hand & 0.006 & 0.506 & 0.494 & 0.297 & 0.587 & 0.577 \\
\hline Forearm & 0.016 & 0.430 & 0.570 & 0.303 & 0.526 & 0.647 \\
\hline Upperarm & 0.028 & 0.436 & 0.564 & 0.322 & 0.542 & 0.645 \\
\hline Forearm and Hand & 0.022 & 0.682 & 0.318 & 0.468 & 0.827 & 0.565 \\
\hline Total arm & 0.050 & 0.530 & 0.470 & 0.368 & 0.645 & 0.596 \\
\hline
\end{tabular}

saturation voltage and over temperature protection. In the circuit diodes D1 to D8 are protection diodes. The state of the motor depends on the logic level of the pins 5, 6, and 7 and 10,11 , and 12 and it is described in the table shown below the circuit diagram.

The diodes D1 to D4 and D5 to D8 provide a safer path for the back e.m.f from the motor to dissipate and thus it protects the corresponding bipolar transistors from damage. The input pins from motor driver are being connected to the microcontroller port pins. When the enable pins of the driver pin are active, then the input signal of the motor driver is amplified to 12 volt and sent to the motor. According to the configuration of port pins, motor moves in clockwise or anticlockwise direction.
In case of BLDC motor controller, every controller has its particular node for distinguishing one from the other. It is possible to control the speed of the motor either by varying the voltage supplied to it or by sending the serial command to it. The speed of the motor is controlled by sending a string of command to the BLDC motor controller serially. Also there is an encoder inside the BLDC motor for getting the angle value simultaneously in a feedback loop.

All the supply voltages are being bypassed through those junction circuits. Actually all voltage sources are being sorted. A 7812 IC voltage regulator is used to convert the $24 \mathrm{~V}$ into $12 \mathrm{~V} \mathrm{DC}$ supply. When the diode connected in junction circuit is in forward bias, it sends the power supply to all driver circuits, but in the opposite case current from driver 


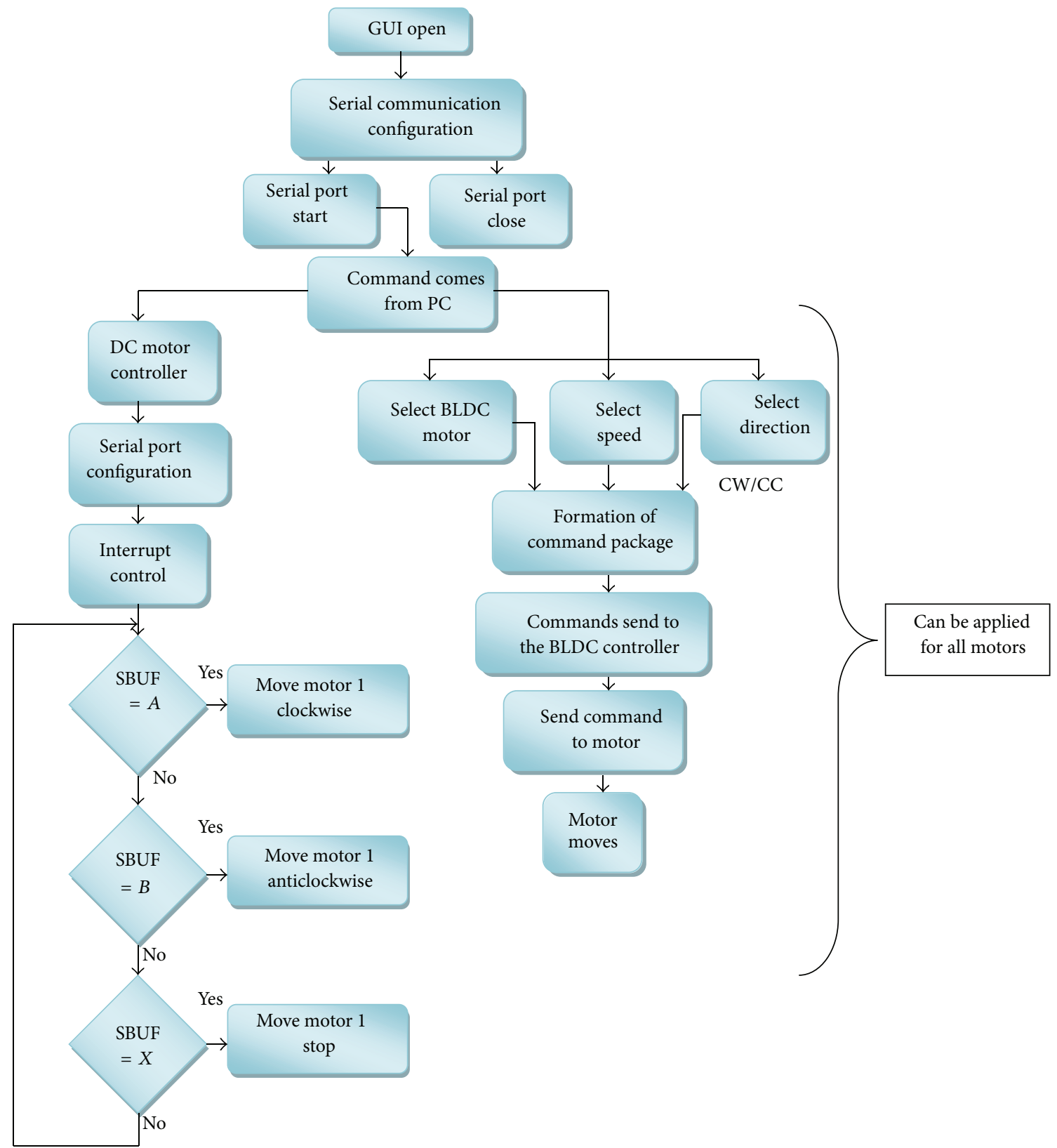

FIgURE 18: Flow chart for PC based control.

circuit cannot be sent to the controller circuit. The flow chart (Figure 18) is showing the logic behind the algorithm.

\section{Graphical User Interface Model of Exorn v.1}

A proper Graphical User Interface (Figure 19) has been developed for controlling all the motions serially through PC based system. It is being designed in Microsoft visual studio platform. The whole GUI model is divided into four divisions. First one is the configuration of serial communication where user has to select the particular COM port and baud rate. It has two buttons for opening and closing of COM port. After opening of COM port, any command can be sent to the serial port. There are three divisions regarding the motion of human joint for proper treatment. Here only one control can be selected out of three options. Selection of one option will freeze the others. The flow chart behind the GUI model is shown in Figure 20.

7.1. Orthopedic Lessons. There are some movements which are generally prescribed by different doctors for stroke patients for different problems. All the motions are stored in memory. After selecting some motion, the patient presses the start button and a command will be sent through serially for taking proper action. It will be updated with time according to orthopedic doctor advice. 


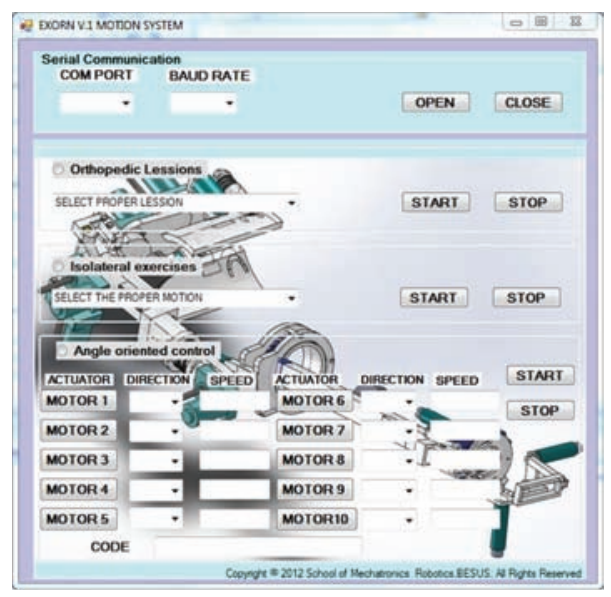

FIGURE 19: GUI model.

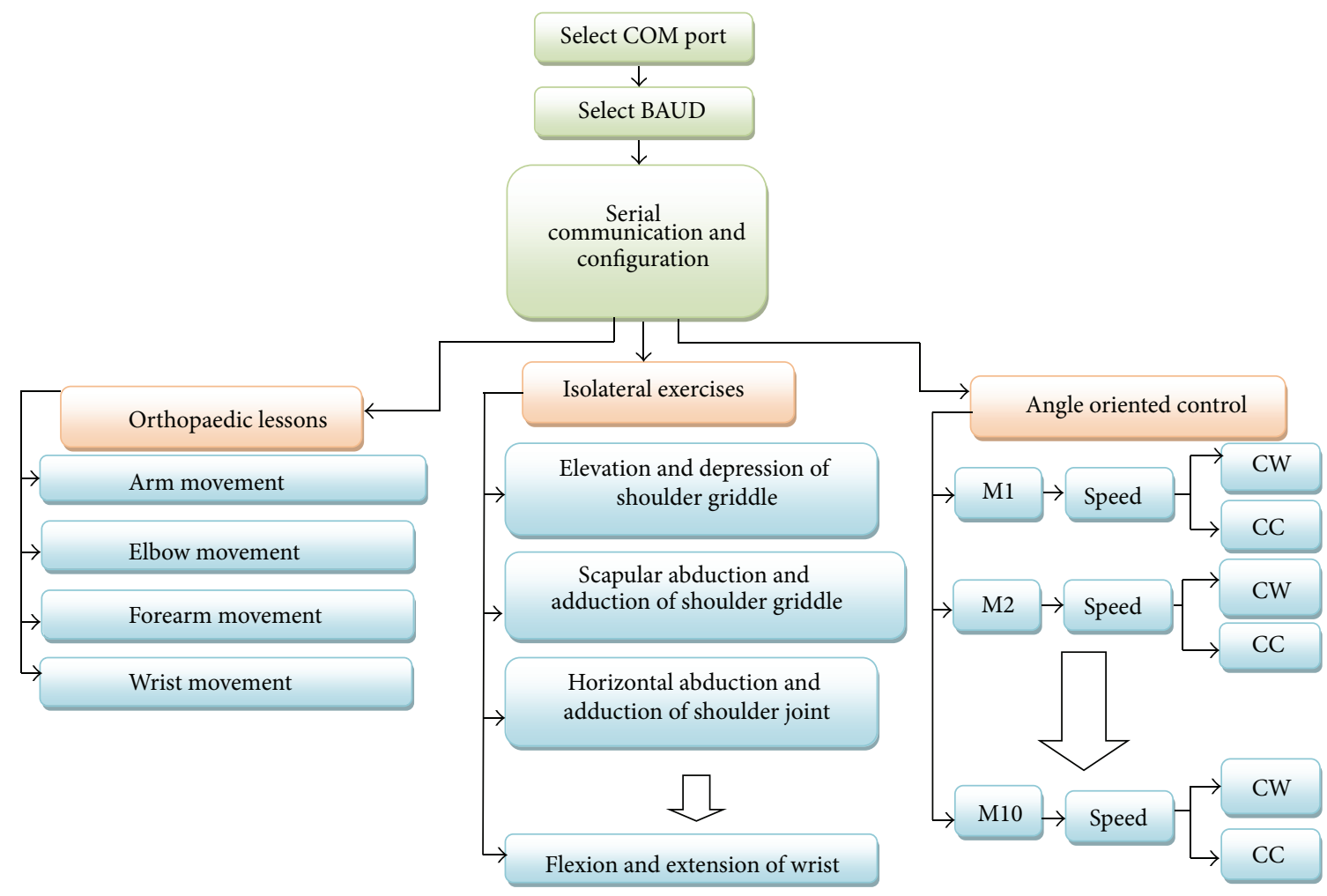

FIgUre 20: Flow chart of GUI model.

7.2. Isolateral Exercises. In isolateral exercises there are some predefined exercises which are standard motions of all joints of human arm. Patients can follow those exercises so that their muscle rigidity becomes less. After each selection a command is being sent serially to master controller. Master controller always takes care of proper actions.

7.3. Angle Oriented Control. In this configuration each joint is controlled in clockwise or anticlockwise manner with different speed. More than one joint can be governed through it. When user selects joint motions, then a frame of command bit serially sends with a start and stop bit to distinguish between different commands. User has to write the required speed beside the box of direction of rotation. In case two motions are contradictory, then the controller does not allow that motion. It is already preprogrammed in the controller.

\section{Predefined Control System}

It is a predefined control (Figure 21). Already a vast schedule of exercise modules is to be loaded in the memory. When someone wants to perform a task, it is being sent to the controller through a manual switch or PC. Master controller will generate a reference trajectory for that particular task. 


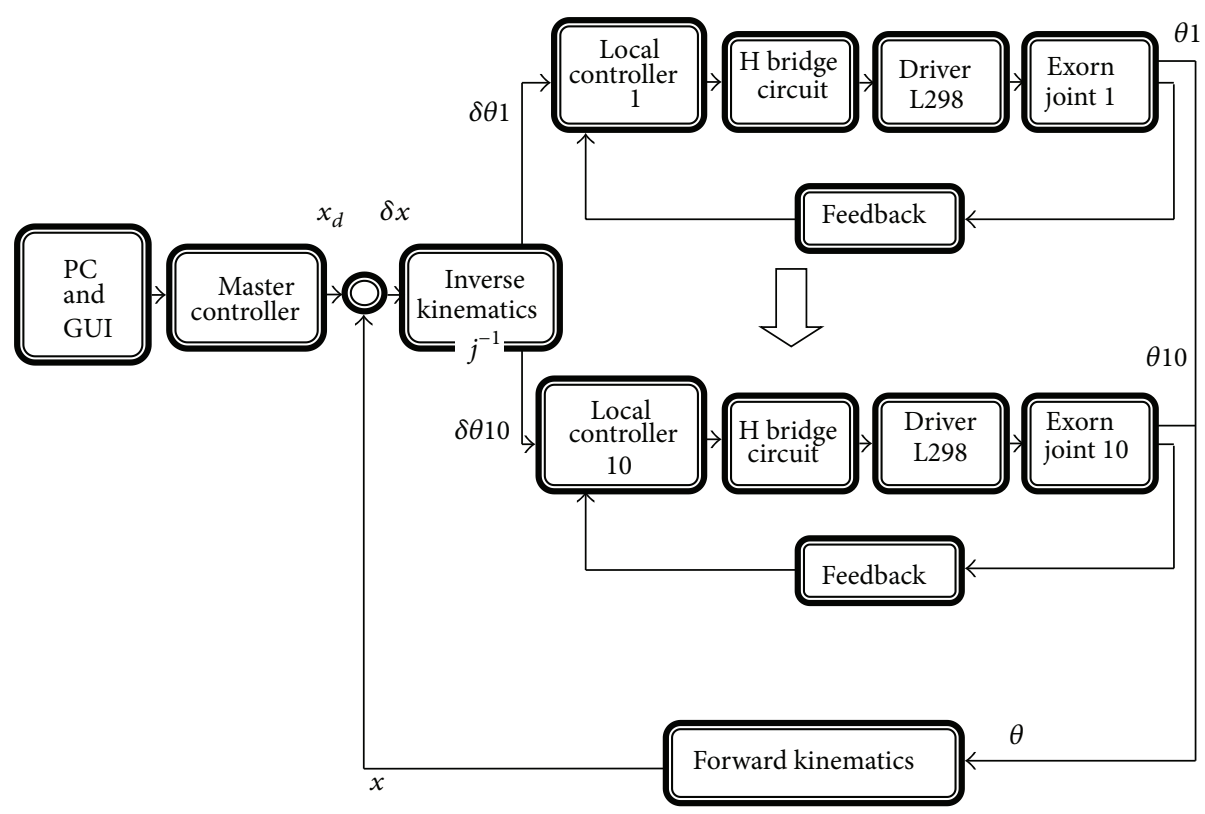

FIGURE 21: Independent joint control system.

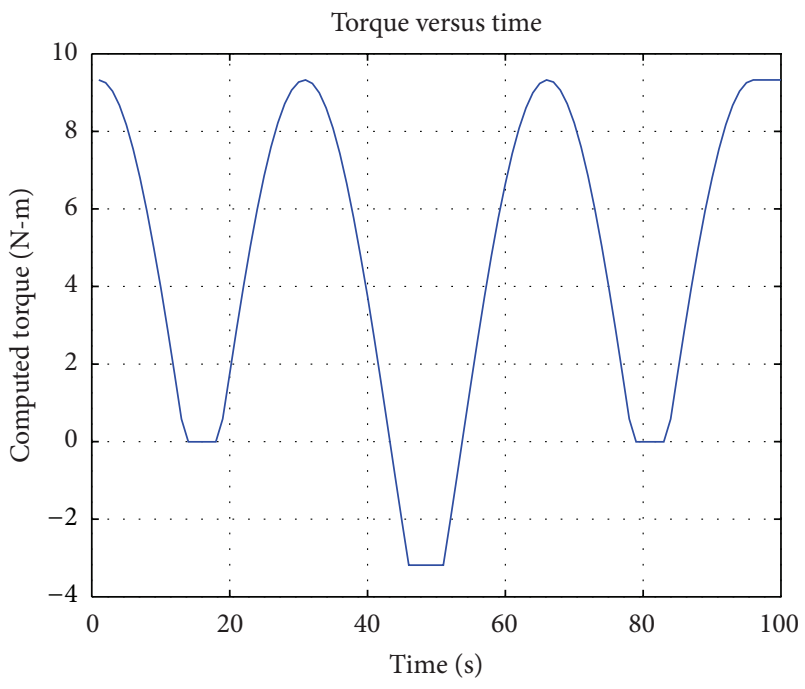

FIGURE 22: Joint torque graph at shoulder due to flexion and extension.

Then it is being sent to the local controller which takes care of that particular trajectory. Always there is feedback loop connected between the system and the master controller. With the help of resolved motion rate control (Whitney 72) approach each joint can be controlled in an independent way. According to forward kinematics the kinematic model can be expressed using the equation

$$
\delta x=J(\theta) \delta \theta .
$$

Outside the singularities the inverse kinematics can be expressed as

$$
\delta \theta=J^{-1}(\theta) \delta x
$$

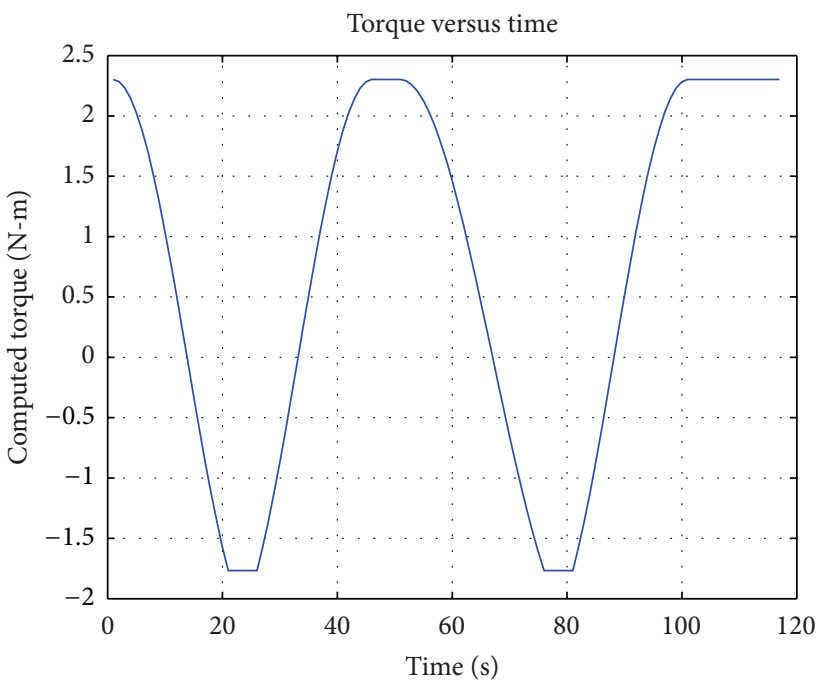

FIgURE 23: Joint torque graph at elbow due to elbow flexion and extension.

There is a relation between task space and joint space. Here the current position at some angle $\theta$ can be expressed as

$$
x=f(\theta) .
$$

The desired location in 3D space is defined as $x_{d}$. So error between current and desired position can be expressed as

$$
\begin{gathered}
\delta x=x_{d}-x, \\
\delta \theta=J^{-1}(\theta) \delta x .
\end{gathered}
$$

The next $\theta$ will be expressed as $\theta^{\prime}=\theta+\delta \theta$. In this way $\theta$ value can be increased or decreased in an iterative way so that 


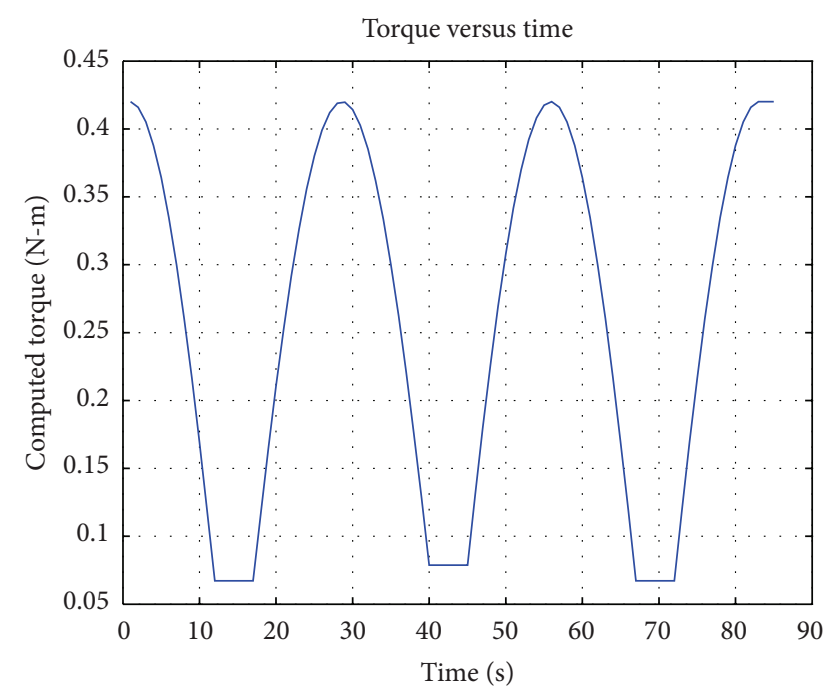

FIGURE 24: Joint torque graph at wrist due to flexion and extension.

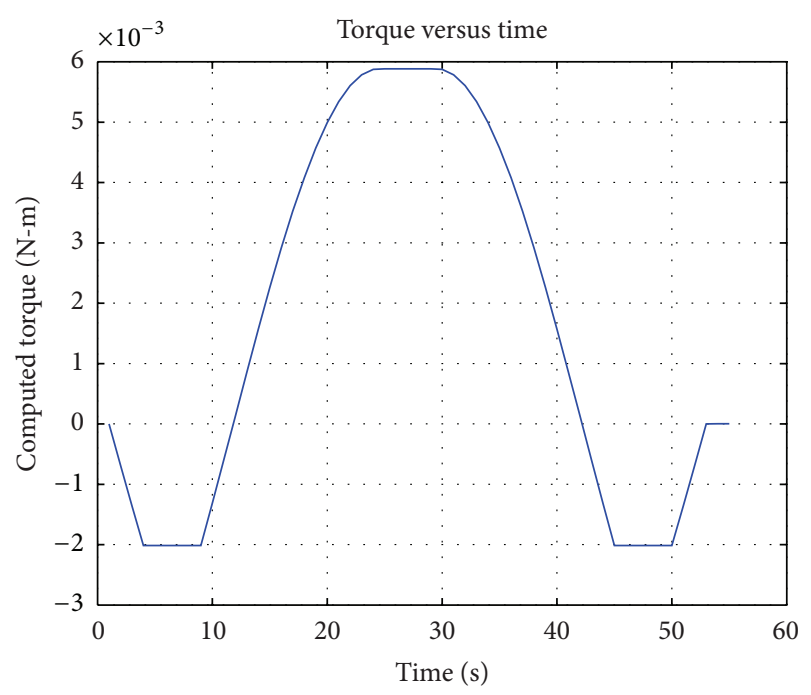

FIGURE 25: Joint torque graph at elbow due to shoulder internal and external rotation.

the desired location can be reached. The error between desired location and current location can be compared using forward kinematics in a feedback loop.

In case of finding inverse kinematics there is a problem of singularity. So we are imposing damped least square method for calculating the inverse kinematics. The damped least squares solutions are intended to ensure a well-conditioned matrix for the solution algorithm while limiting the size of the solution vector $\delta \theta$. This is done by adding a diagonal matrix, $\alpha I$, to the matrix $J J^{T}$. The approximate solution of damped least squares method can be expressed as $\delta \theta=J^{+} \delta x$, where $J^{+}$can be expressed as the equation given below:

$$
J^{+}=J^{T}\left(J J^{T}+\alpha I\right)^{-1}, \quad \alpha \geq 0
$$

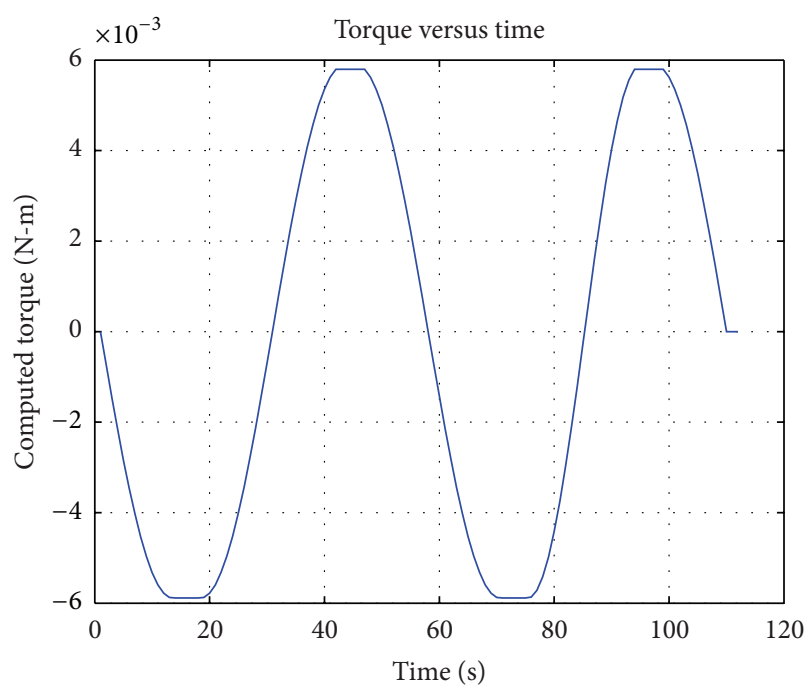

FigURE 26: Joint torque graph at wrist due to elbow pronation and supination.

When this equation is used then the solution satisfies

$$
\frac{\min }{\delta \theta}\left\{\|\delta x-J \delta \theta\|^{2}+\alpha^{2}\|\delta \theta\|^{2}\right\}
$$

where $\|\cdot\|$ denotes the Euclidean norm. For $\alpha=0$ the damped least squares solution will become pseudoinverse solution. Then the Jacobian inverse matrix will be $J^{*}$, where $J^{*}$ become expressed as $J^{T}\left(J J^{T}\right)^{-1}$.

In the damped least squares method, the size of error in the task space is weighed against the size of the resulting solution. For a given $\delta x$ the size of the solution vector is decreased by increasing $\alpha$. However, this is done at the expense of using an approximate solution. As $\alpha$ increases so does the size of the error in the task space. A large $\alpha$ has the other benefit of ensuring a well-conditioned matrix for inversion. It has been shown that the condition number, $K$, of the matrix $P \equiv\left(J J^{T}+\alpha I\right)$, is $K=\left(\sigma_{1}^{2}+\alpha\right) /\left(\sigma_{m}^{2}+\alpha\right)$. Here $\sigma_{1} \geq \sigma_{2} \geq \sigma_{3} \cdots \geq \sigma_{m} \geq 0$ are the singular values of the Jacobian matrix. It can be seen in this equation that $K$ is made arbitrarily close to 1 by increasing $\alpha$, thus ensuring a well-conditioned matrix for inversion even in a singular configuration, where $\sigma_{m}=0$. Simply stated, if one is willing to give up the exactness of the solution then the size of the joint rate can be reduced and a well-conditioned matrix for inversion can be ensured by increasing $\alpha$.

\section{Simulation Results of Torque Level of General Human Arm}

Maximum amount of torque is required to actuate human joints in vertical direction. Here in Figure 25 the torque needed to twist the elbow with respect to shoulder joint is shown. Figure 26 is showing the same kind of motion in wrist 


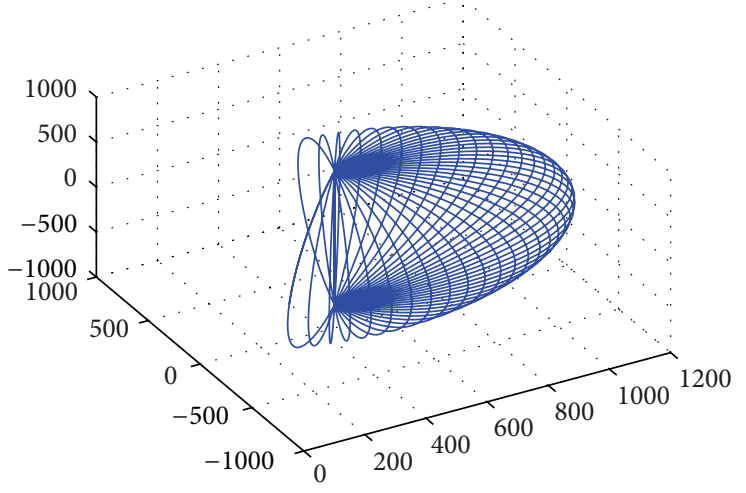

(a)

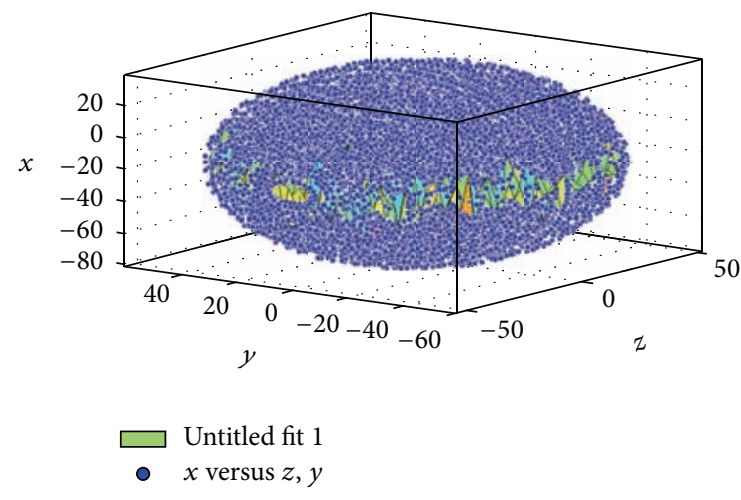

(b)

Figure 27: (a) Outer region covered by Exorn. (b) Workspace covered by Exorn.

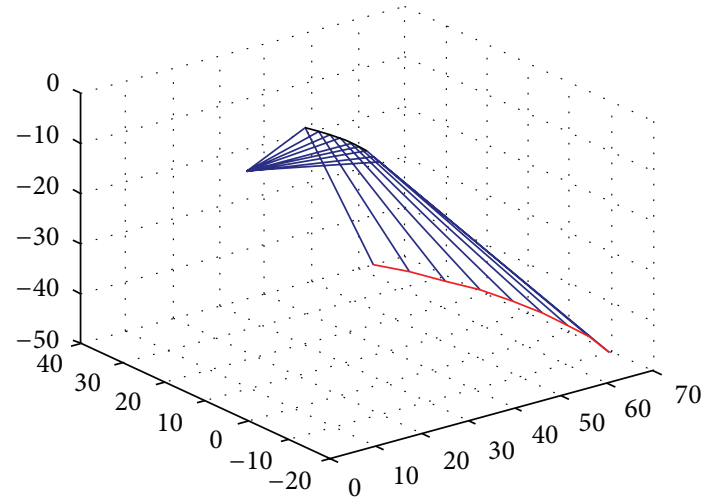

FIGURE 28: Motion due to shoulder griddle.

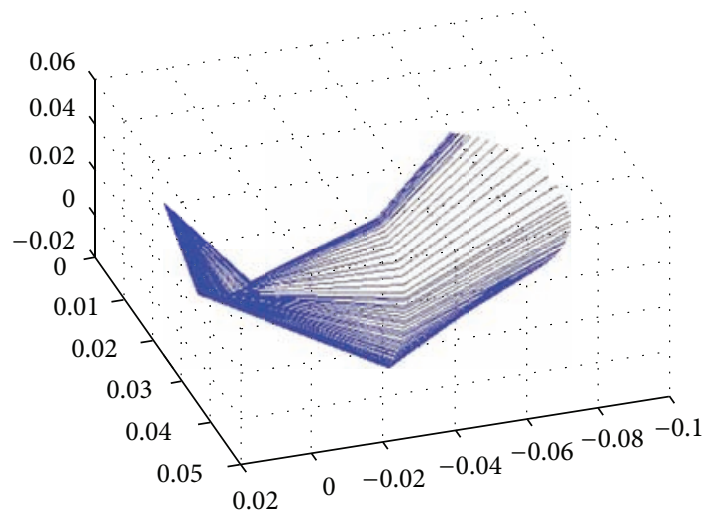

FIGURE 29: Motion due to shoulder griddle, glenohumerals, and elbow joint movement.

joint with respect to the elbow. Figures 22, 23, 24, 25, and 26 will show torque variation in different joints in vertical direction because of proper actuation signal. From those below graphs max. and min. torque for joint actuator can be determined because it is very much essential to select proper motor.

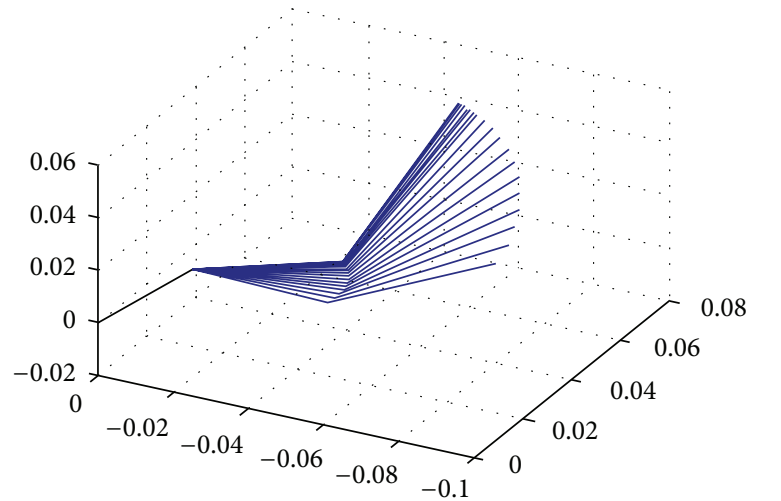

FIGURE 30: Motion due to shoulder joint and elbow joint movement in vertical direction.

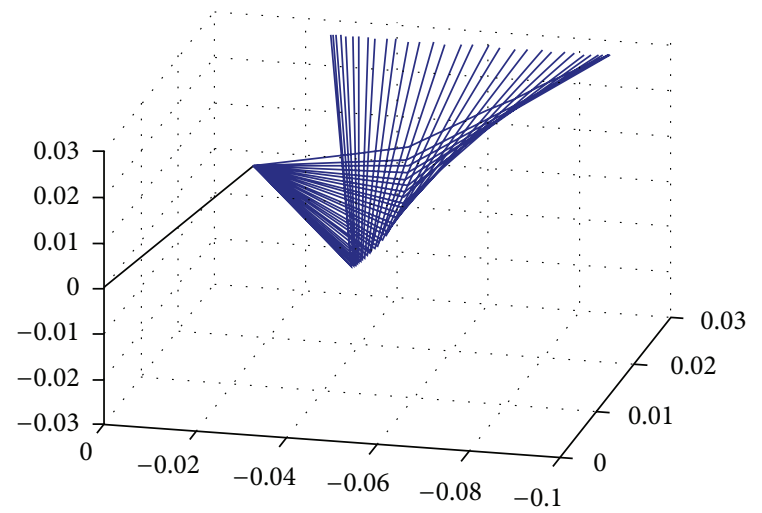

Figure 31: Motion due to glenohumeral joint and elbow joint movement in horizontal direction.

\section{Workspace Calculation and Motion due to Forward Kinematics}

For calculating the workspace of the robotic system, a MATLAB code of nested for loop of all DOFs is being taken with the joint range. It will plot all the reachable points of arm exoskeleton in $3 \mathrm{D}$ space. Figure 27 is showing the outer 
region covered by human hand. Figures 28, 29, 30, and 31 are showing the motion of exoskeleton model due to several joint movements.

\section{Conclusion}

From the above discussion it may be concluded that the developed system is useful for rehabilitation. Comparisons between human joint's range and that of Exorn are already tabulated in Table 1 and the ranges are quite the same for both the cases. If the portable mechanical structure is attached to the human arm, it can be used as an assistive device for the paralyzed people. The 3D model of exoskeleton is already being developed. The model has been fabricated. With the help of the GUI all the motions can be controlled through serial communication. The developed prototype is under working condition. We would like to build the real system so that patient can be benefitted.

\section{References}

[1] J. W. Krakauer, "Arm function after stroke: from physiology to recovery," Seminars in Neurology, vol. 25, no. 4, pp. 384-395, 2005.

[2] T. Nef and R. Riener, "ARMin-design of a novel arm rehabilitation robot," in Proceedings of the IEEE 9th International Conference on Rehabilitation Robotics (ICORR '05), pp. 57-60, July 2005.

[3] S. J. Ball, I. E. Brown, and S. H. Scott, "MEDARM: a rehabilitation robot with 5DOF at the shoulder complex," in Proceedings of the IEEE/ASME International Conference on Advanced Intelligent Mechatronics (AIM '07), September 2007.

[4] M. Mistry, P. Mohajerian, and S. Schaal, "Arm movement experiments with joint space force fields using an exoskeleton robot," in Proceedings of the IEEE 9th International Conference on Rehabilitation Robotics (ICORR '05), pp. 408-413, July 2005.

[5] A. Schiele and F. C. T. van der Helm, "Kinematic design to improve ergonomics in human machine interaction," IEEE Transactions on Neural System and Rehabilitation, vol. 14, no. 4, pp. 1534-4320, 2006.

[6] S. J. Ball, I. E. Brown, and S. H. Scott, "A planar 3DOF robotic exoskeleton for rehabilitation and assessment," in Proceedings of the 29th Annual International Conference of IEEE-EMBS, Engineering in Medicine and Biology Society (EMBC '07), pp. 4024-4027, August 2007.

[7] I. Sardellitti, E. Cattin, S. Roccella et al., "Description, characterization and assessment of a bio-inspired shoulder jointfirst link robot for neuro-robotic applications," in Proceedings of the 1st IEEE/RAS-EMBS International Conference on Biomedical Robotics and Biomechatronics (BioRob '06), pp. 112-117, February 2006.

[8] Source-winter, Biomechanics and Motor Control of Human Motion, ISBN-978-0470398180, 2010.

[9] C.-J. Yang, B. Niu, J.-F. Zhang, and Y. Chen, "Different structure based control system of the PUMA manipulator with an arm exoskeleton," in Proceedings of the IEEE Conference on Robotics, Automation and Mechatronics, pp. 572-577, December 2004.

[10] K. Kiguchi, T. Tanaka, K. Watanabe, and T. Fukuda, "Exoskeleton for human upper-limb motion support," in Proceedings of the IEEE International Conference on Robotics and Automation, pp. 2206-2211, September 2003.
[11] T. H. Massie and K. J. Salisbury, "PHANToM haptic interface: a device for probing virtual objects," in Proceedings of the International Mechanical Engineering Congress and Exposition, pp. 295-299, November 1994.

[12] C. Carignan and K. Cleary, "Closed-loop force control for haptic simulation of virtual environments," The Electronic Journal of Haptics Research, vol. 2, no. 2, pp. 1-14, 2000.

[13] A. Frisoli, F. Rocchi, S. Marcheschi, A. Dettori, F. Salsedo, and M. Bergamasco, "A new force-feedback arm exoskeleton for haptic interaction in virtual environments," in Proceedings of the First Joint Eurohaptics Conference and Symposium on Haptic Interfaces for Virtual Environment and Teleoperator Systems, pp. 195-201, 2005.

[14] D. Lawrence, "Impedance control stability properties in common implementations," in Proceedings of the IEEE International Conference on Robotics and Automation, pp. 1185-1190, 1988.

[15] A. Nakai, Y. Kunii, H. Hashimoto, and F. Harashima, "Arm type haptic human interface: sensor arm," in Proceedings of the International Conference on Artificial Reality and Tele-Existence (ICAT), pp. 77-84, Tokyo, Japan, December 1997. 

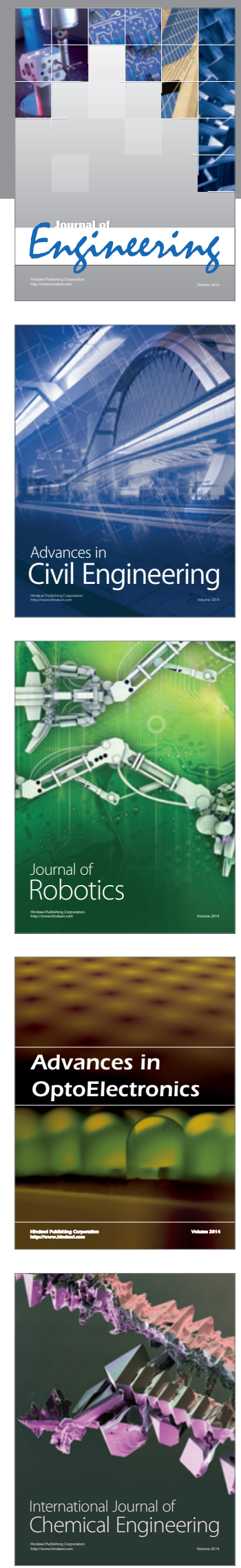

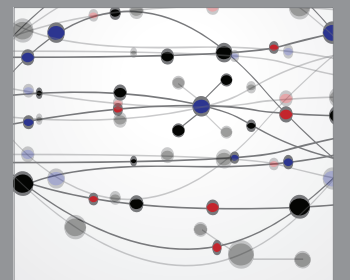

The Scientific World Journal
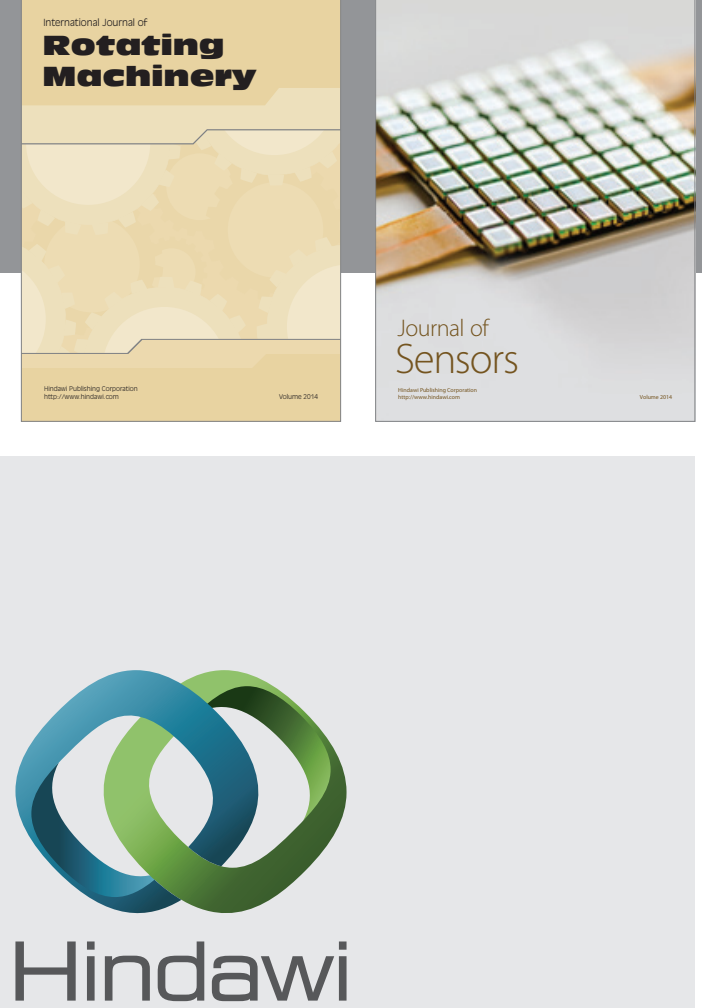

Submit your manuscripts at http://www.hindawi.com
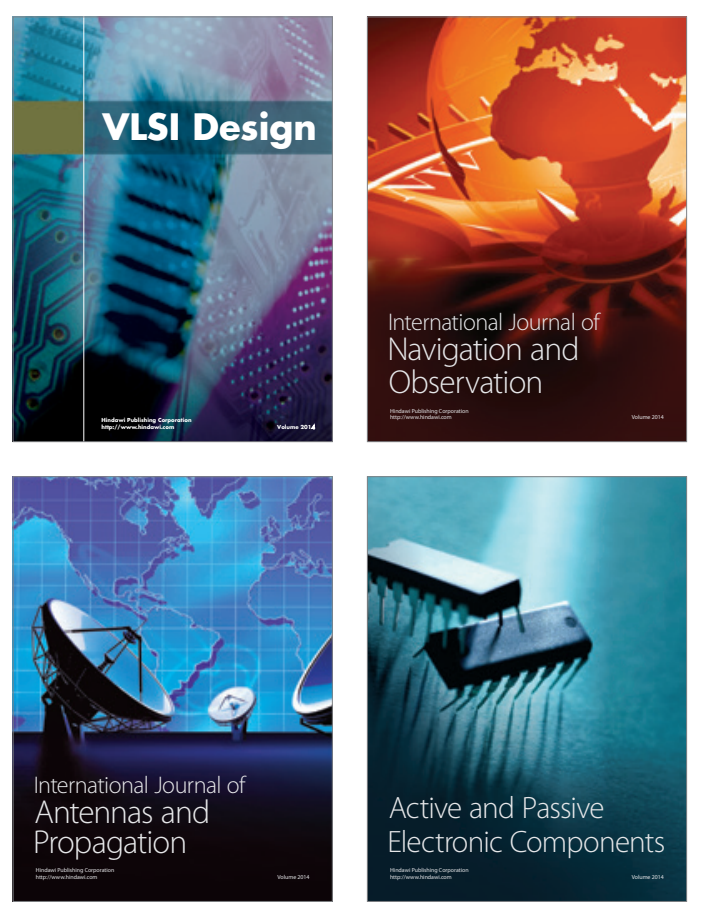
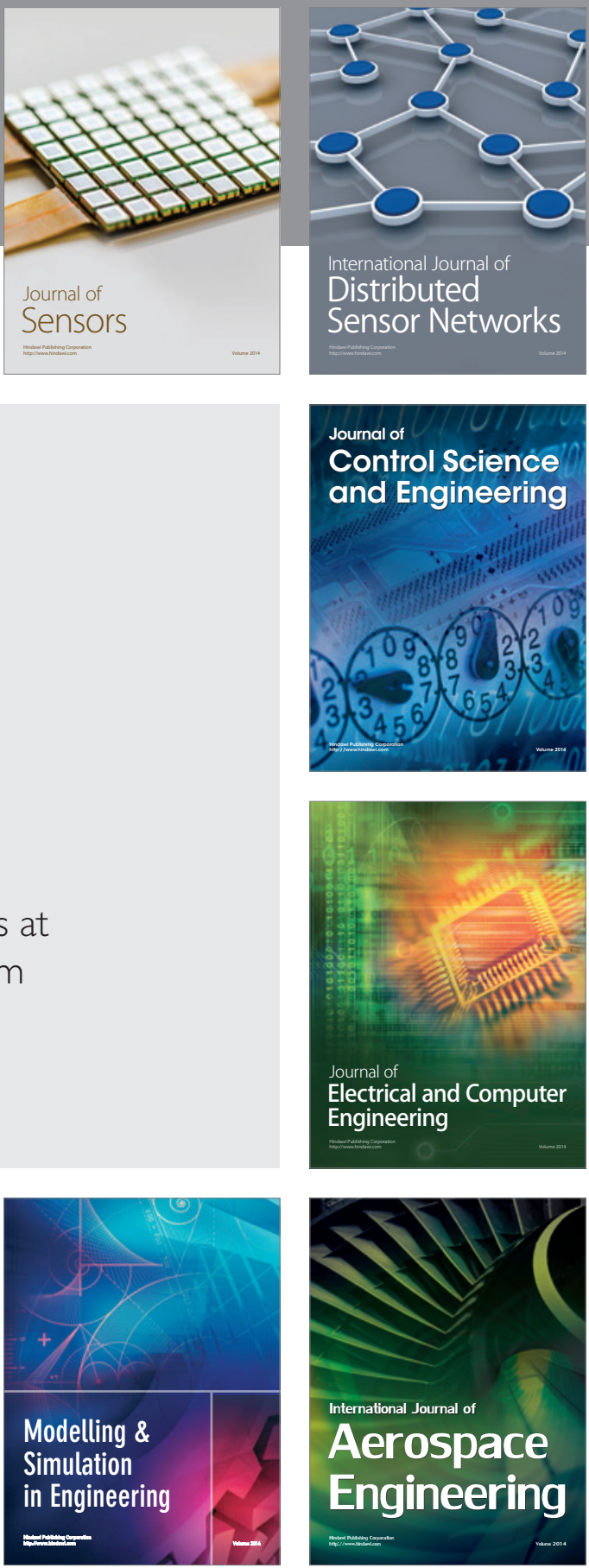

Journal of

Control Science

and Engineering
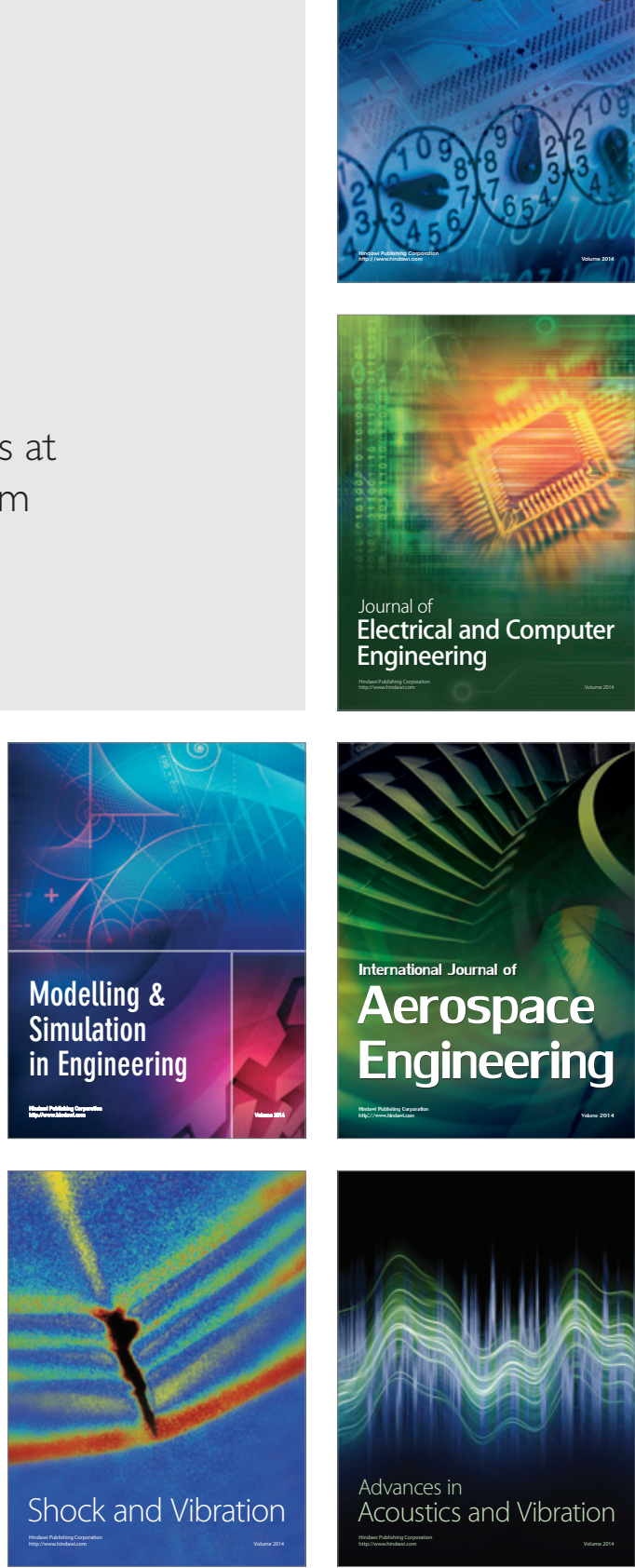